\title{
Advanced Age Dissociates Dual Functions of the Perirhinal Cortex
}

\author{
Sara N. Burke, ${ }^{1,2}$ Andrew P. Maurer, ${ }^{1,2}$ Saman Nematollahi, ${ }^{1,2}$ Ajay Uprety, ${ }^{1,2}$ Jenelle L. Wallace, ${ }^{1,2}$ \\ and Carol A. Barnes s, $^{1,3}$ \\ ${ }^{1}$ Evelyn F. McKnight Brain Institute, ${ }^{2}$ Arizona Research Laboratories Division of Neural Systems Memory and Aging, and ${ }^{3}$ Departments of Psychology, \\ Neurology and Neuroscience, University of Arizona, Tucson, Arizona 85724
}

The perirhinal cortex (PRC) is proposed to both represent high-order sensory information and maintain those representations across delays. These cognitive processes are required for recognition memory, which declines during normal aging. Whether or not advanced age affects the ability of PRC principal cells to support these dual roles, however, is not known. The current experiment recorded PRC neurons as young and aged rats traversed a track. When objects were placed on the track, a subset of the neurons became active at discrete locations adjacent to objects. Importantly, the aged rats had a lower proportion of neurons that were activated by objects. Once PRC activity patterns in the presence of objects were established, however, both age groups maintained these representations across delays up to $2 \mathrm{~h}$. These data support the hypothesis that age-associated deficits in stimulus recognition arise from impairments in high-order stimulus representation rather than difficulty in sustaining stable activity patterns over time.

\section{Introduction}

The perirhinal cortex (PRC) processes, represents, and stores high-order sensory information that is critical for a wide range of behaviors (Murray and Wise, 2012). The PRC enables, for example, fear-conditioning to a stimulus (Kholodar-Smith et al., 2008) or a context (Bucci et al., 2000), and paired-associative learning (Higuchi and Miyashita, 1996). The PRC also supports an animal's ability to discriminate between novel and familiar stimuli (Málková et al., 2001; McTighe et al., 2010). A number of these cognitive functions are altered during normal aging, including observations that aged rats are more likely to incorrectly identify a novel stimulus as familiar (Burke et al., 2010) and show poorer consolidation of information in fear conditioning (Oler and Markus, 1998).

Although there is no loss of PRC neurons with age (Rapp et al., 2002), several biochemical and molecular alterations within the PRC of old animals have been identified that may contribute to cognitive deficits. First, protein composition is altered, including a reduction in the expression of the NR2A subunit of the NMDA receptor in aged compared with young rats (Liu et al., 2008). Moreover, old rats have reduced immunoreactivity for calbindin-D28k in PRC principal cells (Moyer et al., 2011), and overall glutamate levels are lower in the aged PRC (Liu et al., 2009). Finally, following object exploration,

\footnotetext{
Received July 5, 2013; revised Oct. 17, 2013; accepted Nov. 14, 2013.

Author contributions: S.N.B. and C.A.B. designed research; S.N.B., S.N., A.U., and J.L.W. performed research; S.N.B. and A.P.M. analyzed data; S.N.B., A.P.M., and C.A.B. wrote the paper.

This work was supported by the McKnight Brain Research Foundation, and National Institutes of Health Grants AG012609, NS054465, NS070464, and HHMI5205889. Additionally, we thank Kim Bohne, Jie Wang, Michael Montgomery, Michelle Carroll, and Luann Snyder for help with completing this manuscript.

Correspondence should be addressed to Carol A. Barnes, Evelyn F. McKnight Brain Institute, Life Sciences North Building, Room 362, University of Arizona, Tucson, Arizona 85724. E-mail: caro@@nsma.arizona.edu.

DOI:10.1523/JNEUROSCI.2875-13.2014

Copyright $\odot 2014$ the authors $\quad 0270-6474 / 14 / 340467-14 \$ 15.00 / 0$
}

fewer PRC neurons in old rats transcribe the activitydependent immediate-early gene Arc (Burke et al., 2012b), which encodes an effector protein critical for AMPA receptor trafficking (Chowdhury et al., 2006).

In freely behaving young rats, PRC principal neurons show firing rate increases at locations adjacent to objects (Burke et al., 2012a; Deshmukh et al., 2012). This activity remains consistent as objects become familiar and across delays (Burke et al., 2012a). It is probable that this object-specific activity is a critical physiological correlate of stimulus recognition. The age-associated decline in the proportion of PRC neurons that transcribe Arc predicts that old rat PRC cells may show reduced object-associated spiking. Because Arc expression has been shown to be decoupled from neuronal activity under some conditions in which rats show learning impairments (Fletcher et al., 2006), it is also possible that old PRC neuron firing remains normal despite the fact that fewer cells show Arc expression during this activity. Because Arc expression is critical for memory maintenance (Guzowski et al., 2000), such a decline could lead to deficits in stable activity patterns across delays.

The aim of the current experiment was to determine the extent to which age-associated declines in PRC-dependent behavior arise from deficits in stimulus representation, maintenance, or both. PRC neurons were recorded as young and aged rats traversed a circular track that was empty or contained objects for two epochs separated by a delay. If objectassociated neuron firing is similar between age groups, then it can be assumed that old rats have a deficit in inducing Arc transcription that may result in unstable activity patterns across delays. On the other hand, if there are alterations in the pattern of PRC cell activity in response to objects, then it could be inferred that advanced age results in impaired PRCdependent stimulus representation. 


\section{Materials and Methods}

Subjects and behavioral training. All behavioral procedures were in accordance with the National Institutes of Health guidelines for rodents and protocols approved by the University of Arizona Institutional Animal Care and Use Committee. Electrophysiological studies were conducted on six young (8-10 months old), and six aged (24-27 months old) Fisher-344 male rats. All rats participated in these experiments in pairs of one young rat and one aged rat such that a single old-young pair arrived in the colony in the same batch of animals, went through identical behavior procedures on the same days, and underwent surgical implantation within $24 \mathrm{~h}$ of each other. The rats were housed individually and maintained on a $12 \mathrm{~h}$ light/dark cycle. Before rats were implanted with the hyperdrive recording device, they were screened for spatial memory impairments and normal vision using the Morris swim task (Morris, 1984). All animals were tested over $4 \mathrm{~d}$ with six spatial trials on each day. Animals were then screened for visual ability with $2 \mathrm{~d}$ of cued visual trials (6 trials/d) in which the escape platform was above the surface of the water but the position of the platform changed between each trial. This procedure has been described in detail previously (Barnes et al., 1996). Rats' performance on the swim task was analyzed offline with either in-house software (WMAZE, M. Williams) or a commercial software application (ANY-maze). Because different release locations and differences in swimming velocity produce variability in the latency to reach the escape platform, a corrected integrated path length (CIPL) was calculated to ensure comparability of the rats' performance across different release locations (Gallagher et al., 1993). The CIPL value measures the cumulative distance over time from the escape platform corrected by an animal's swimming velocity, and is equivalent to the cumulative search error described by Gallagher and colleagues (1993). Therefore, regardless of the release location, if the rat mostly swims toward the escape platform, the CIPL value will be low. In contrast, the more time a rat spends swimming in directions away from the platform, the higher the CIPL value.

During electrophysiological recordings, the animals were fooddeprived to $\sim 85 \%$ of their ad libitum weight and trained to run on a circular track $(\sim 335 \mathrm{~cm}$ in circumference) in both the counterclockwise and clockwise directions for food reinforcement. The food reward was a mixture of rat food pellets made soft by soaking them in water, applesauce, and the diet supplement Ensure. All electrophysiological recordings took place during the dark phase of the rats' light/dark cycle. Food rewards were given in a small plastic food dish $(4 \times 4 \mathrm{~cm})$ at two positions on the track. Both food dishes were located at the position on the track that marked the completion of one lap on opposite sides of a barrier; that is, where the rat was required to turn around and run in the opposite direction (Fig. 1A). During all electrophysiological recording sessions, rats were required to run at least 20 laps (10 in the counterclockwise direction and 10 in the clockwise direction) during two distinct episodes of behavior. Each track-running epoch was flanked by a rest period in which the rat was placed in a towel-lined pot located in a position that was central to the circumference of the track. Thus, the activity of PRC neurons was monitored during an initial rest session (before behavior), during the first epoch of track running, during a second rest session after Epoch 1 that was either $20 \mathrm{~min}$ or $2 \mathrm{~h}$ long, during a second epoch of track running, and then finally during a third rest period. Data from the rest periods were used to assess firing stability across the entire recording session.

All 12 rats participated in the same behavioral procedures. During the first procedure (Day 1), rats ran on an empty track (no objects-both epochs; Fig. 1A) for both epochs of behavior. A 20 min rest period occurred between Epoch 1 and Epoch 2. For the second procedure (Day 2), during Epoch 1, eight novel objects that varied in size, color, and texture were placed at eight different locations along the track. All the objects used in these experiments were at least $7 \mathrm{~cm}$ in each dimension, so as to be easily identified by the rats. The side of the track on which the objects were placed alternated between the left and the right side and the rat had to run past these objects to obtain the food reward. This also ensured that the rats had to briefly attend to the objects while traversing the track to avoid colliding with them. Following either a $20 \mathrm{~min}$ or a $2 \mathrm{~h}$ rest period, during Epoch 2, six of the same objects used in Epoch 1 remained in the
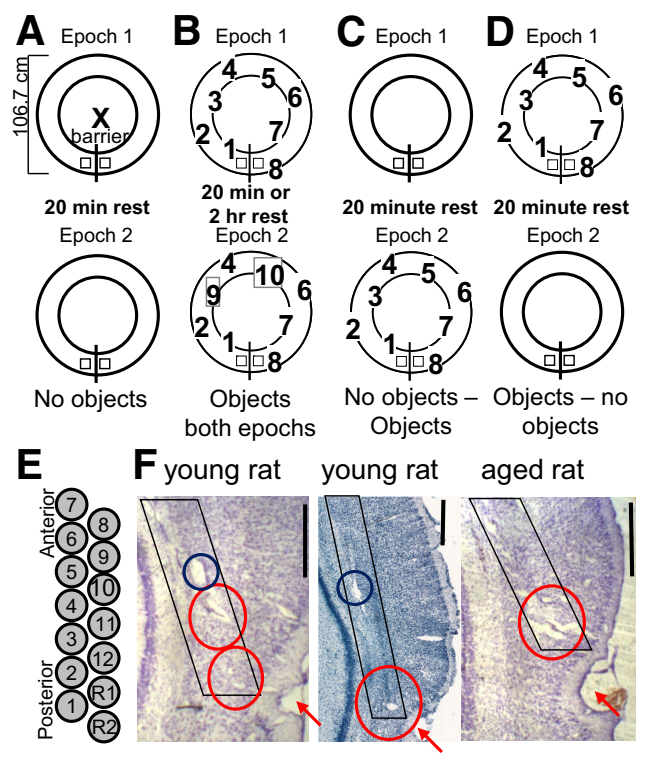

Figure 1. Behavioral procedures used during electrophysiological recordings. The track used for behavior during all electrophysiological recordings required rats to run 20 laps bidirectionally (10 counterclockwise, 10 clockwise) for a food reward. $\boldsymbol{A}$, Under the no objects condition the track was empty during both epochs of track running. Rewards were given in two food dishes located on opposite sides of a barrier (indicated by squares), at the position where the rat was required to turn around. The " $X$ " indicates the location of the pot that the rat was placed in during rest episodes. $\boldsymbol{B}$, In the objects-both epochs condition, eight novel objects were placed at discrete locations around the track for the first epoch of behavior (top), and the rat had to run past the objects to obtain the food reward. During the second epoch of behavior (bottom), six of the eight objects used in Epoch 1 were placed on the track at the same location as in Epoch 1, while two of the eight objects were removed and substituted with two novel objects (in this case Objects 3 and 5 were replaced with 0 bjects 9 and 10 as indicated by the gray boxes). C, D, All rats participated in two additional behavioral procedures: the no objects-objects $(\boldsymbol{C})$ and the objects-no objects $(\boldsymbol{D})$ conditions. $\boldsymbol{E}$, A schematic view of bottom of the tetrode guide cannulae showing an example of the configuration of the recording probes. The numbers indicate tetrode assignment, which was used for determining the recording location of each tetrode. $\boldsymbol{F}$, Coronal Nissl-stained sections of two young rat brains (left and middle), and one aged rat brain (right) showing representative tetrode tracks (black lines) and lesions (red circles) for perirhinal cortical recordings. In the young rats, the tetrodes recorded neurons in Layer V (left) and Layers II/III (left and right). In the aged rats, most perirhinal cortical neurons were recorded from Layer $V$. The red arrows indicate the location of the rhinal sulcus. Scale bars, $\sim 1 \mathrm{~mm}$. In some cases the tetrodes did not reach the PRC (blue circles) and cells recorded from these tetrodes were not used in the current analyses.

same location on the track and two objects that were on the track during Epoch 1 were replaced with two novel objects (objects-both epochs condition; Fig. 1B). This manipulation was included to control for any differences that object novelty could have on firing rate before it was shown that changing the objects and their relative novelty have minimal effects on PRC neuron activity (Burke et al., 2012a). Each rat completed these behavioral procedures on consecutive days, and this process was repeated a minimum of two times and a maximum of six times. Eight novel objects were always used for Epoch 1 of the $20 \mathrm{~min}$ and $2 \mathrm{~h}$ delay conditions. Yoked old-young rats pairs that underwent electrophysiological recordings on the same days were always presented with identical objects in the same location. Different aged-young rat pairs were presented with distinct novel objects such that across yoked pairs of animals, objects sets were not the same. For one aged rat only, no single-unit data were collected for the objects-both epochs condition with a $2 \mathrm{~h}$ delay. Following the completion of these behavioral procedures, all rats traversed the track for two additional control conditions to measure the extent to which objects modulated PRC activity within the same population of principal cells. This included a no objects-objects condition (Fig. 1C) and an objects-no objects condition (Fig. $1 D$ ) that rats participated in on different days than the conditions described above. For both of these procedures, Epochs 1 and 2 were separated by a 20 min delay. 
Table 1. Number and cell layer of PRC single units recorded from each young and aged rat over all conditions

\begin{tabular}{|c|c|c|c|c|c|c|}
\hline Rat & Age & $\begin{array}{l}\text { Number (cell layer) } \\
\text { No objects }\end{array}$ & 20 min delay & $2 \mathrm{~h}$ delay & No objects-no objects & Objects-no objects \\
\hline 8412 & Young & $7(V)$ & $8(V)$ & $11(\mathrm{~V})$ & $9(\mathrm{~V})$ & $2(\mathrm{v})$ \\
\hline 8413 & Aged & $62(V)$ & $34(V)$ & $45(V)$ & $9(\mathrm{~V})$ & $13(V)$ \\
\hline 8509 & Young & $7(\mathrm{~V})$ & $14(V)$ & $12(\mathrm{~V})$ & $9(\mathrm{~V})$ & $4(\mathrm{~V})$ \\
\hline 8507 & Aged & $20(V)$ & $17(\mathrm{~V})$ & & $7(\mathrm{~V})$ & $6(V)$ \\
\hline 8583 & Young & $93(\mathrm{II} / \mathrm{III})$ & 94 (II/III) & $83(\mathrm{II} / \mathrm{III})$ & $50(\mathrm{II} / \mathrm{III})$ & $53(\mathrm{II} / \mathrm{III})$ \\
\hline 8615 & Aged & $99(\mathrm{~V})$ & $56(V)$ & $62(V)$ & $55(\mathrm{~V})$ & $17(\mathrm{~V})$ \\
\hline 8661 & Young & 34 and 14 (II/III and V) & 33 and 12 (II/III and V) & 25 and 10 (II/III and V) & 1 and 26 (II/III and V) & 1 and 25 (II/III and V) \\
\hline 8662 & Aged & $99(\mathrm{~V})$ & $41(\mathrm{~V})$ & $59(\mathrm{~V})$ & $33(V)$ & $63(\mathrm{~V})$ \\
\hline 8670 & Young & 60 and 68 (II/III and V) & 48 and 58 (II/III and V) & 21 and 27 (II/III and V) & 11 and 15 (II/III and V) & 28 and $29(\mathrm{II} / \mathrm{II}$ and $\mathrm{V})$ \\
\hline 8696 & Aged & $39(\mathrm{~V})$ & $44(\mathrm{~V})$ & $27(\mathrm{~V})$ & $30(\mathrm{~V})$ & $44(\mathrm{~V})$ \\
\hline 8883 & Young & $35(\mathrm{~V})$ & $30(\mathrm{~V})$ & $12(\mathrm{~V})$ & $3(V)$ & $2(\mathrm{~V})$ \\
\hline 8865 & Aged & 7 and 31 (II/III and V) & 4 and 44 (II/III and V) & 2 and 35 (II/III and V) & $16(V)$ & 3 and 26 (II/III and V) \\
\hline Total & & 675 & 537 & 431 & 274 & 316 \\
\hline
\end{tabular}

For all conditions in which objects were placed on the track, the objects were fixed in place using Velcro. Thus, rats could actively explore, rear, and climb on the objects without displacing them. Additionally, during all rest periods the objects were removed from the track so that the rat could not see them during the intervening delay period.

Surgical procedures. Surgery was conducted according to National Institutes of Health guidelines for rodents and protocols approved by the University of Arizona Institutional Animal Care and Use Committee. Before surgery, the rats were administered penicillin $\mathrm{G}(30,000 \mathrm{U}$, i.m., in each hindlimb) to combat infection. During surgical implantation, the rats were maintained under anesthesia with isoflurane administered at doses ranging from 0.5 to $2.5 \%$.

All rats were implanted with a "hyperdrive" manipulator device that held an array of 14 separately moveable tetrode recording probes (Gothard et al., 1996). Each hyperdrive consisted of 14 drive screws coupled by a nut to a guide cannula. Twelve of these cannulae contained tetrodes (McNaughton et al., 1983b; Recce and O'Keefe, 1989), fourchannel electrodes constructed by twisting together four strands of insulated $13 \mu \mathrm{m}$ nichrome wire (H.P. Reid). Two additional tetrodes had their individual wires shorted together, and the shorted tetrode with the least cellular activity was used as an indifferent reference. A full turn of the screw advanced the tetrode $318 \mu \mathrm{m}$ and all tetrodes were lowered between 4.0 and $6.0 \mathrm{~mm}$ ventral to the surface of brain. The 14 guide cannulae were arranged in two linear columns of seven each such that the configuration of tetrodes spanned $\sim 2 \mathrm{~mm}$ from the anterior to posterior position (Fig. 1E). This permitted sampling of neurons from a greater extent of the PRC and enabled more precise matching of tetrode number to track and lesion location for histological verification or recording sites (see below).

The implant was cemented in place with dental acrylic anchored by small screws. Immediately after surgery, all tetrodes were lowered $\sim 1$ $\mathrm{mm}$ into the cortex, and rats were orally administered $26 \mathrm{mg}$ of acetaminophen (Children's Tylenol Elixir or ibuprofen) for analgesia. Oral administration of acetaminophen was continued for 3-5 d after surgery. Additionally, all rats were given either $25 \mathrm{mg}$ of ampicillin (Bicillin, Wyeth Laboratories) or a combination of $20 \mathrm{mg}$ of sulfamethoxale and $0.4 \mathrm{mg}$ of trimethoprin (Hi-Tech Pharmacal) on a $10 \mathrm{~d}$ on/10 d off regimen for the duration of the experiment.

In all rats, recordings were made from the middle to caudal PRC region (between 4.0 and $6.5 \mathrm{~mm}$ posterior, $6.0 \mathrm{~mm}$ lateral to bregma, and angled $14^{\circ}$ toward the midline). Following experimental procedures, 20 $\mu \mathrm{A}$ of direct current was administered to each tetrode. One to 2 weeks following microlesioning, rats were given a fatal dose pentobarbital and perfused with $4 \%$ paraformaldehyde (Gage et al., 2012). Brains were extracted and soaked in a $30 \%$ sucrose solution for 1 week or until they sank. Tissue was then frozen with dry ice and the area under the cranial implant was coronally sliced at $40 \mu \mathrm{m}$ with a cryostat. Sections were directly mounted to superfrost slides and dried overnight in a fume hood. Finally, tissue was Nissl-stained and tetrode location was verified. In most cases the tetrode tracks were not parallel to the plane of sectioning and tracks had to be followed over several adjacent slides. In these cases the section in which the lesion was the largest was considered the approximate location. Only the units recorded from tetrodes histologically verified to be in the PRC were used in the current analyses and neurons recorded from other brain regions (e.g., ventral CA1 or area TE of the inferotemporal cortex) were excluded. The majority of tetrodes were located in Area 36 of the PRC, but in two young and two aged rats four tetrodes reached Dorsal Area 35. Moreover, in the young rats neurons were recorded from both Layer V and Layers II/III, but for the aged rats only one rat had tetrodes in Layers II/III, and all of the other single-unit recordings were from neurons in Layer $V$. Figure $1 F$ shows Nissl-stained coronal sections from different young and aged rat brains with representative tetrode recording tracks and lesions within the PRC. Neurons recorded from tetrodes that produced lesions outside of the PRC were not included in any of the current analyses. In most cases these tracks were in Area TE (Fig. 1F, blue circles).

Neurophysiology. After surgery, tetrodes were lowered into the PRC over several weeks. The neutral reference electrode was advanced with other tetrodes and when an area of cortex was reached that did not record any unit activity, it was not moved again. The four channels of each tetrode were attached to a 50-channel unity-gain head stage (Neuralynx). A multiwire cable connected the head stage to digitally programmable amplifiers (Neuralynx). The spike signals were amplified by a factor of $1000-5000$, bandpass-filtered between $600 \mathrm{~Hz}$ and $6 \mathrm{kHz}$, and transmitted to the Cheetah data acquisition system (Neuralynx). Signals were digitized at $32 \mathrm{kHz}$, and events that reached a predetermined threshold were recorded for a duration of $1 \mathrm{~ms}$. Spikes were sorted offline on the basis of the amplitude and principal components from the four tetrode channels by means of a semiautomatic clustering algorithm (KlustaKwik, K.D. Harris). The resulting classification was corrected and refined manually with custom-written software (MClust, A.D. Redish, University of Minnesota; updated by S.L. Cowen, University of Arizona, and D.R. Euston, University of Lethbridge), resulting in a spike-train time series for each of the well isolated cells. No attempt was made to match cells from one daily session to the next. Therefore, the numbers of recorded cells reported does not take into account possible recordings from the same cells on consecutive days and the actual number of unique recorded neurons could be lower than reported in Table 1. Note that all statistics were run on the basis of pooled data for individual rats, and not with total cells as the sample size. This conservative approach was used as a means to not create a bias from oversampling the same neuron.

Putative principal neurons in the deep and superficial layers of the PRC were identified by means of their waveform characteristics and autocorrelogram features (Barthó et al., 2004). Specifically, neocortical principal cells tend to have autocorrelograms with peaks at 3-6 ms followed by an exponential decay, which is indicative of "bursting" cells, or an autocorrelogram with an exponential rise from 1 to 10 s of milliseconds. These cells are considered regular-spiking neurons. In contrast, the autocorrelograms of putative interneurons are not as fast decaying or slow rising as those of pyramidal neurons (Barthó et al., 2004).

Activity from putative principal neurons was used for analysis only if their respective waveform features showed clear separation from the 
spikes of other cells and from noise. This was initially determined with qualitative ratings made by experimenters. Following this rating, the extent that clusters obtained from the waveforms of neurons included in the present analyses showed separation from other cells and from noise was quantified by calculating the $\mathrm{L}$ ratio and isolation distance of each cluster (Schmitzer-Torbert et al., 2005). The L ratio is the degree that a cluster separates from other spikes recorded on the same tetrode normalized by the total number of spikes for a given cluster. A lower L-ratio value is indicative of better separation (Schmitzer-Torbert et al., 2005). The average $\mathrm{L}$ ratio was 0.15 ( $\pm 0.02 \mathrm{SEM}$ ) for the young rats and 0.11 $( \pm 0.02$ SEM) for the aged rats, which was not significantly statistically different $\left(t_{(5)}=1.22, p=0.28\right.$; paired samples). The isolation distance estimates how distant the cluster spikes are from the other spikes recorded on the same tetrode (Harris et al., 2001). Higher isolation distance therefore corresponds to better separation and a reduced probability of contamination from noise or spikes from other neurons. The mean isolation distance was 68.9 ( \pm 20.9 SEM) for the young rats and $55.7( \pm 5.1$ SEM) for the aged rats, which was not significantly different $\left(_{(5)}=0.58\right.$, $p=0.59$; paired samples). These values indicate that cluster quality was not different between the young and aged rats and that all cells used in the current analyses showed intermediate to good separation (SchmitzerTorbert et al., 2005).

Several diodes were mounted on the head stage to allow position tracking. The position of the diode array was detected by a TV camera placed directly above the experimental apparatus and recorded with a sampling frequency of $60 \mathrm{~Hz}$. The sampling resolution was such that a pixel was $\sim 0.3 \mathrm{~cm}$. A portion of the principal data obtained from the young rats during the no objects-both epochs and objects-both epochs conditions has been published previously (Burke et al., 2012a).

Analyses and statistics. Spike-activity diagrams were constructed by plotting the circular trajectories of the animals on a linearized, onedimensional scale, using a linear interpolation (Maurer et al., 2005). For each cell, the maximum firing rate, mean firing rate, and information content (spikes/bit) were calculated. Maximum and mean firing rates were obtained after normalizing spike activity by the occupancy of the animal, and information content was calculated from 161 bins of $\sim 4.1$ cm with the following formula: $\Sigma P_{\mathrm{i}}\left(R_{\mathrm{i}} / R\right) \log _{2}\left(R_{\mathrm{i}} / R\right)$, where $P_{\mathrm{i}}$ was the probability of occupancy for a bin, $R_{\mathrm{i}}$ was the firing rate of the bin, and $R$ was the mean firing rate of the cell (Skaggs et al., 1993). The area of the track within seven bins of a food dish $(28.7 \mathrm{~cm})$ was excluded for the calculation of information content, because when the rats were within this area of the track, their running speed was either zero or it was changing rapidly as the rat was stopping to obtain reward or accelerating after eating. Moreover, this area of the track contained a food dish, the reward and an object during conditions with objects. Therefore, activity at this location could presumably be related to the food dish, reward, the ripple activity known to occur during behavior when animals pause (O'Neill et al., 2006), and/or the object. Because it was difficult to dissociate the relative contribution of these factors, activity in this area of the track was excluded from analysis. It is notable, however, that when a velocity filter of $10 \mathrm{~cm} / \mathrm{s}$ was applied to spikes, the firing rates at the food dish regions did not significantly vary between object and no object conditions and between other regions on the track (data not shown). This suggests that activity in these areas were related to stimulus properties rather to reward.

When the information content was calculated for all cells that showed activity on the maze (a mean firing rate $>0.2$ spikes/bin occupancy), there was not a significant difference in mean information content between Epochs 1 and $2\left(t_{(45)}=0.10, p=0.94\right.$; paired-samples $t$ test). Moreover, when all behavioral conditions were analyzed for the three rats (two young and one aged) that had tetrodes in both the deep and the superficial layers of the PRC, information content was not significantly different $\left(t_{(5)}=1.51, p=0.19\right.$; paired-samples $t$ test $)$ between neurons in Layer V ( 0.61 bits/spike) and neurons in Layers II/III ( 0.53 bits/spike). Therefore, the data obtained from the different epochs of track running, and from the different cortical laminae were combined for additional analysis of the effects of behavioral condition and age.

Information content was used to examine the activity correlates of PRC neurons. Specifically, it was observed that many PRC neurons show in- creased firing rates at the location of objects (Burke et al., 2012a; Deshmukh et al., 2012). These patterns of activity were termed "object fields" (Burke et al., 2012a), and a PRC neuron was considered to have an object field if its information content was $>0.5$ bits/spike, and the occupancy-normalized mean firing rate within a bin exceeded the mean firing rate for $\geq 4$ consecutive bins (Burke et al., 2012a). Using the criteria described above, the mean size of object fields was $26.9 \mathrm{~cm}$ in the young rats and $26.1 \mathrm{~cm}$ in the aged rats, and object field size did not vary significantly across age group and behavioral epoch $\left(F_{(3,15)}=0.68, p>0.58\right.$; repeated measures). Moreover, the proportion of neurons with object fields was not significantly different between Epoch 1 and Epoch 2 for any of the behavioral conditions $\left(F_{(1,42)}=\right.$ $0.04, p=0.85$; repeated-measures ANOVA). Therefore, the data were collapsed across epoch for the age comparison.

The correlated activity patterns between epochs were quantified by dividing the track into 80 bins of $\sim 4.1 \mathrm{~cm}$, and the firing rate of an individual neuron was calculated for each bin. Laps that the rats ran in the counterclockwise direction were separated from laps where the running direction was clockwise. Therefore, the firing rate was determined for a total of 160 bins resulting in a $160 \times 1$ firing-rate vector. The Pearson's correlation coefficient between the Epoch 1 and the Epoch 2 firing-rate vectors was then calculated for all PRC neurons across the six different behavioral conditions in the two age groups.

To examine any possible age-related differences, the mean for all cells was calculated for every rat. This reduced the chances that the analysis would be skewed because more neurons were recorded from some rats than others or because recordings were taken from the same cells over multiple days. This conservative approach also safeguarded against a bias toward finding an age difference due to the high statistical power obtained by the large number of cells. Finally, because data were always obtained from yoked pairs of young-aged rats, repeated-measures or paired statistical analyses (Spatz, 2011) were used for significance testing and $\alpha$ was set to the 0.05 level. This analysis approach has been used previously for in vivo high-density electrophysiology studies comparing age groups (Insel et al., 2012; Schimanksi et al., 2013).

\section{Results}

\section{Recognition behavior and spatial learning}

The aged rats had impaired spatial learning compared with the young animals, but were equally able to use visual cues to guide behavior, as measured by the Morris swim task (Fig. 2). Rats have a natural tendency to explore objects, or other stimuli, that are novel (Ennaceur and Delacour, 1988). Therefore, decreased running velocity during track traversals can be used as an indication of novel object detection, as animals will stop to explore new objects, while faster speeds suggest stimulus recognition. To test this idea, the rats' velocities during the first two laps were compared with the last two laps for epochs in which the track contained no objects, novel objects (Epoch 1 for the objects-both epochs conditions), and familiar objects (Epoch 2 of objectsboth epochs condition; Fig. $3 A$ ). When the mean running speed of the rats for the first two laps was compared with the velocity for last laps, statistical analysis revealed that the rats ran significantly slower during the first laps relative to the last laps $\left(F_{(1,20)}=14.23\right.$, $p<0.001$; repeated measures). There was also a significant effect of behavioral condition on the difference in running velocity between the first and last laps $\left(F_{(3,60)}=7.59, p<0.01\right.$; repeatedmeasures ANOVA), which did not significantly interact with age group $\left(F_{(1,20)}=1.91, p=0.18\right.$; repeated measures $)$. Post hoc analysis indicated that the difference in running speeds between the first laps and the last laps was greatest when there were novel objects on the track compared with the other conditions $(p<$ 0.005 for all comparisons, Tukey HSD). This indicates that both the young and aged animals showed the same pattern of reduced running speed when novel objects were on the track compared with when the track contained familiar objects or was empty. In 


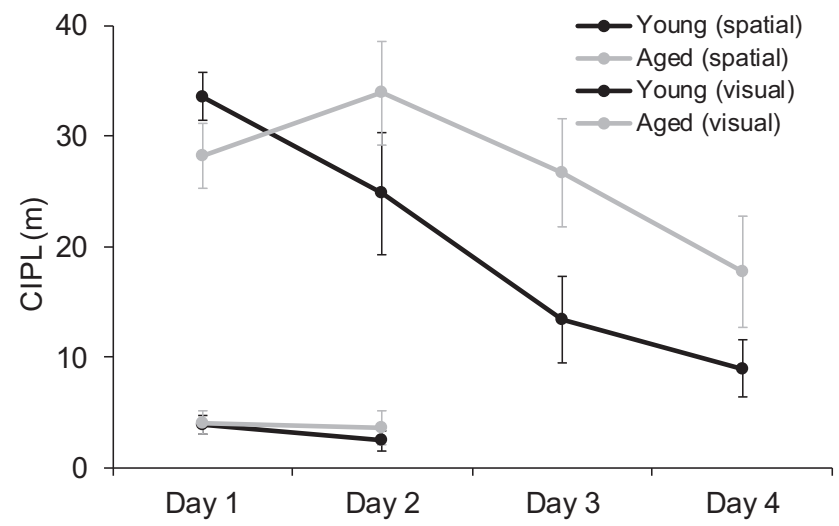

Figure 2. Performance on the Morris swim task. The results from the Morris swim task for the adult (black) and the aged (gray) rats. The $x$-axis is the day of testing and the $y$-axis is the mean CIPL score. Higher CIPL scores indicate longer path lengths to reach the escape platform. All rats completed $4 \mathrm{~d}$ of spatial trials (solid lines), in which the platform was hidden below the surface of the water, followed by $2 \mathrm{~d}$ of visually cued trials (dashed lines), in which the platform was visible but its location changed after every trial. During the spatial trials, the aged rats had significantly longer CIPL scores compared with the adult rats $\left(F_{(1,40)}=6.12, p<0.02\right.$; ANOVA). Post hoc analysis revealed that this difference was due to the aged rats having significantly longer CIPL scores on Days 3 and 4 of spatial testing ( $p<0.05$ for all comparisons; Tukey HSD) while there was no significant difference in the path lengths between young and aged rats on Day 1 or Day 2 of spatial testing ( $p>0.2$ for both comparisons; Tukey HSD). The (IPL scores of all rats were significantly decreased when the platform was visible, and there was no significant effect of age on the CIPL values during either Day 1 or Day 2 of the visual swim task testing $\left(F_{(1,10)}\right.$ $=0.07, p=0.79$; repeated-measures ANOVA). Therefore, it is unlikely that any of the aged animals used in the current series of experiments had significant visual impairment relative to the young group. Error bars represent \pm 1 SEM.

other words, the aged rats expressed behavior that was indicative of object recognition similar to the young rats.

To further examine whether there was a difference between novel and familiar objects on running speed, a discrimination index was calculated for epochs in which the objects were novel and became familiar during later laps (novel-familiar) and for epochs in which the objects were familiar during all laps (familiar-familiar). The discrimination index was the difference in running speed between the first two laps and the last two laps divided by the mean running speed. Figure $3 B$ shows the discrimination index across behavioral condition for young and aged rats. There was a significant effect of novel-familiar versus familiar-familiar on the discrimination index $\left(F_{(1,11)}=5.23, p<0.001\right.$; repeated measures). This indicates that across all animals the running speeds between the first and last laps decreased more when objects were initially novel and became familiar compared with when familiar objects were on the track for the first laps. Age group, however, did not have a significant effect on the discrimination index $\left(F_{(1,11)}=1.25, p=0.24\right.$; repeated measures). Moreover, there was not a significant interaction between age and behavioral condition $\left(F_{(1,11)}=0.64, p=0.5\right.$; repeated measures $)$. These results confirm the observation that both young and aged rats were able to recognize when objects were familiar and that this corresponded with reduced running speeds during laps in which the track contained novel objects.

\section{Object-related activity of perirhinal cortical neurons across the life span}

The activity of 1643 PRC principal neurons was monitored in this experiment. An additional 590 neurons were recorded during the control no objects-objects and objects-no objects conditions
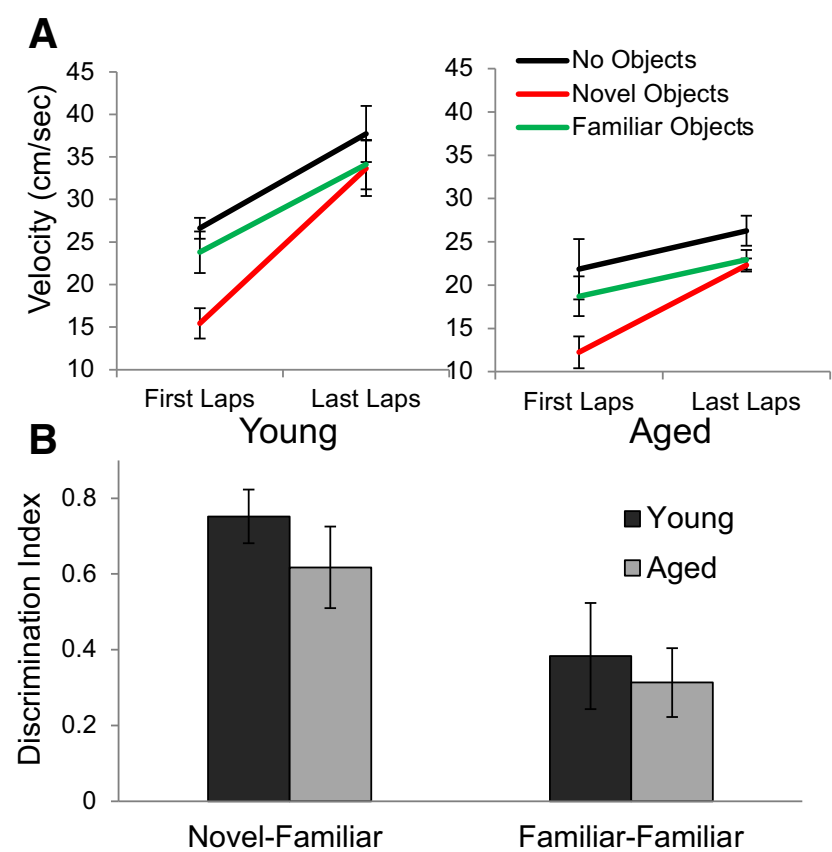

Figure 3. Running velocity of young and aged rats for the different behavioral conditions. $A$, Comparison of running speed during the first laps (Laps 1 and 2) versus the last laps segregated by epochs without objects (black), with novel objects (red), and with familiar objects (green) for young (left) and aged (right) rats. All rats ran significantly slower during the first laps relative to the last laps $\left(F_{(1,20)}=14.23, p<0.001\right.$; repeated measures $)$. The difference in running speeds between the first laps and the last laps was greatest when there were novel objects on the track compared with the other conditions ( $p<0.005$ for all comparisons, Tukey HSD). $\boldsymbol{B}$, The discrimination index (difference in first and last lap velocity/mean velocity) for epochs in which the objects were novel and became familiar during later laps (Novel-Familiar) and epochs in which the objects were familiar (Familiar-Familiar) during all laps in young (black) and aged (gray) rats. There was a significant effect of Novel-Familiar versus Familiar-Familiar on the discrimination index $\left(F_{(1,11)}=5.23, p<0.001\right.$; repeated measures). Age group did not have a significant effect on the discrimination index $\left(F_{(1,11)}=1.25, p=0.24\right.$; repeated measures), and there was no significant interaction between age and behavioral condition $\left(F_{(1,11)}=0.64, p=\right.$ 0.5 ; repeated measures). Error bars represent \pm 1 SEM.

(Table 1). The numbers of PRC neurons that were recorded during these experiments were not significantly different between the young and the aged rats $\left(F_{(1,19)}=0.03, p=0.87\right)$. Additionally, all single-unit neurons that were included in the current analyses showed stability during an entire recording session, and there was no significant difference in the mean firing rate of neurons during Rest 1 and Rest $3\left(F_{(1,10)}=1.01, p=0.34\right.$; repeated-measures ANOVA). Moreover, the stability of the mean firing rates between the beginning of a recording session and the end of a recording session was not significantly different between young and aged rats $\left(F_{(1,10)}=0.02, p=0.67\right.$; repeated-measures ANOVA). The mean firing rate during sleep episodes was $1.3 \mathrm{~Hz}$ for the young rats and $1.1 \mathrm{~Hz}$ for the aged rats, and these firing rates were not statistically different from each other $\left(F_{(1,10)}=\right.$ $2.26, p=0.16)$. The firing rates of neurons recorded from different cortical lamina also did not systematically differ $\left(t_{(6)}=1.23\right.$, $p=0.23$, paired-samples $t$ test), and the data were collapsed between the deep and superficial layers for subsequent analyses (Table 2). Finally, age group did have a significant effect on the mean firing rate during behavior $\left(F_{(1,40)}=22.52, p<0.001\right.$; repeated-measures ANOVA), but not on maximum firing rate $\left(F_{(1,40)}=0.31, p=0.58\right.$; repeated-measures ANOVA). Table 3 shows the $p$ values for age comparisons of the mean and maximum firing rates for the different behavioral conditions and age groups. 
Table 2. Firing rates in different cortical laminae ${ }^{a}$

\begin{tabular}{|c|c|c|c|c|c|c|c|}
\hline Young & No objects & 20 min delay & $2 \mathrm{~h}$ delay & Aged & No objects & 20 min delay & $2 \mathrm{~h}$ delay \\
\hline 8412 & $0.8(\mathrm{~V})$ & $2.7(\mathrm{~V})$ & $0.9(\mathrm{~V})$ & 8413 & $1.0(\mathrm{~V})$ & $1.2(\mathrm{~V})$ & $0.9(\mathrm{~V})$ \\
\hline 8509 & $0.8(\mathrm{~V})$ & $1.7(\mathrm{~V})$ & $1.6(\mathrm{~V})$ & 8507 & $1.0(\mathrm{~V})$ & $1.1(\mathrm{~V})$ & \\
\hline 8583 & $1.7(\mathrm{II} / \mathrm{III})$ & $1.2(\mathrm{II} / \mathrm{III})$ & 1.5 (II/III) & 8615 & $1.2(\mathrm{~V})$ & $1.0(\mathrm{~V})$ & $0.9(\mathrm{~V})$ \\
\hline 8661 & 2.8 and $1.3(\mathrm{II} / \mathrm{II}$ and $\mathrm{V})$ & 3.0 and $3.3(\mathrm{II} / \mathrm{II}$ and $\mathrm{V})$ & 2.2 and $1.2(\mathrm{II} / \mathrm{III}$ and $\mathrm{V})$ & 8662 & $1.2(\mathrm{~V})$ & $1.3(\mathrm{~V})$ & $1.6(\mathrm{~V})$ \\
\hline 8670 & 2.0 and $2.4(\mathrm{II} / \mathrm{III}$ and $\mathrm{V})$ & 1.6 and $1.6(\mathrm{II} / \mathrm{III}$ and $\mathrm{V})$ & 1.5 and $2.1(\mathrm{II} / \mathrm{III}$ and $\mathrm{V})$ & 8696 & $1.3(\mathrm{~V})$ & $1.8(\mathrm{~V})$ & $0.8(\mathrm{~V})$ \\
\hline 8883 & $1.6(\mathrm{~V})$ & $1.1(\mathrm{~V})$ & $0.7(\mathrm{~V})$ & 8865 & 3.3 and 1.1 (II/III and V) & 3.4 and $0.8(\mathrm{II} / \mathrm{II}$ and $\mathrm{V})$ & 0.7 and $0.8(\mathrm{II} / \mathrm{II}$ and $\mathrm{V})$ \\
\hline
\end{tabular}

${ }^{a}$ Mean firing rate $(\mathrm{Hz})$ of cells recorded from pairs of young and aged rats. Layers in parentheses.

Table 3. Firing rate characteristics of PRC neurons recorded in young and aged rats

\begin{tabular}{lllll}
\hline & 20 min delay & 2 h delay & No objects & $p$ value \\
\hline $\begin{array}{l}\text { Mean firing rate } \\
\quad \text { Young rats }\end{array}$ & $1.84 \pm 0.21 \mathrm{~Hz}$ & $1.44 \pm 0.20 \mathrm{~Hz}$ & $1.59 \pm 0.19 \mathrm{~Hz}$ & $p=0.33$ \\
$\begin{array}{l}\text { Aged rats } \\
p \text { value }\end{array}$ & $1.26 \pm 0.09 \mathrm{~Hz}$ & $1.00 \pm 0.11 \mathrm{~Hz}$ & $1.21 \pm 0.06 \mathrm{~Hz}$ & $p=0.16$ \\
$\begin{array}{l}\text { Maximum firing rate } \\
\quad\end{array}$ & $p<0.05$ & $p<0.05$ & $p<0.05$ & \\
$\begin{array}{l}\text { Young rats } \\
\text { Aged rats }\end{array}$ & $5.31 \pm 0.31 \mathrm{~Hz}$ & $5.48 \pm 0.60 \mathrm{~Hz}$ & $4.25 \pm 0.33 \mathrm{~Hz}$ & $p=0.07$ \\
$p$ value & $4.78 \pm 0.10 \mathrm{~Hz}$ & $4.69 \pm 0.18 \mathrm{~Hz}$ & $4.97 \pm 0.24 \mathrm{~Hz}$ & $p=0.24$ \\
\hline
\end{tabular}

In the hippocampus, the firing rate of CA1 pyramidal neurons is modulated by velocity (McNaughton et al., 1983a; Maurer et al., 2005) in both young and old animals (Shen et al., 1997). Therefore, a possible explanation for the higher mean firing rates of young compared with aged PRC neurons could be different running velocities between age groups (Fig. 3). When firing rate was compared with velocity in the aged rats for velocities between 3 and $51 \mathrm{~cm} / \mathrm{s}$, it was observed that, similar to young animals, running speed did not significantly modulate PRC neuron firing rate during any of the behavioral conditions (Fig. 4). These data suggest that the firing-rate difference between young and old rats cannot be accounted for by the aged rats' slower running speeds. Moreover, it confirms previous observations that, in contrast to neurons in the hippocampus (McNaughton et al., 1983a; Maurer et al., 2005) and medial entorhinal cortex (Sargolini et al., 2006), PRC neuron firing rates are not modulated by velocity (Burke et al., 2012a).

An alternative explanation for the decreased firing rates in aged compared with young rats could be found in the differential effect of relative novelty and familiarity on PRC neuron firing rates (Zhu and Brown, 1995; Zhu et al., 1995). Specifically, it has been hypothesized that aged rats (Robitsek et al., 2008) and humans (Daselaar et al., 2006) may have an enhanced familiarity signal in the PRC that could possibly compensate for a decline in hippocampal-dependent recollection. Recent data from young animals, however, have not observed an effect of novel versus familiar stimuli on the firing rates of PRC principal neurons (Burke et al., 2012a; Thome et al., 2012; Woloszyn and Sheinberg, 2012). The possibility remains that aged PRC principal neurons may show decremental activity patterns as stimuli go from being novel to familiar. Thus, the firing rate was measured across laps for Epochs 1 and 2 of the different behavioral conditions, and then was normalized within a cell by calculating the $Z$-score firing rate for each lap. The normalized firing rate change between the first and last laps within an epoch for the counterclockwise and clockwise laps was then quantified. There was no systematic change in the normalized firing rate over laps during any of the behavioral conditions for either the young or the aged rats $\left(F_{(15,120)}=0.41, p=0.97\right.$; repeated-measures ANOVA $)$. Moreover, the change in normalized firing rate between Lap 1 and the
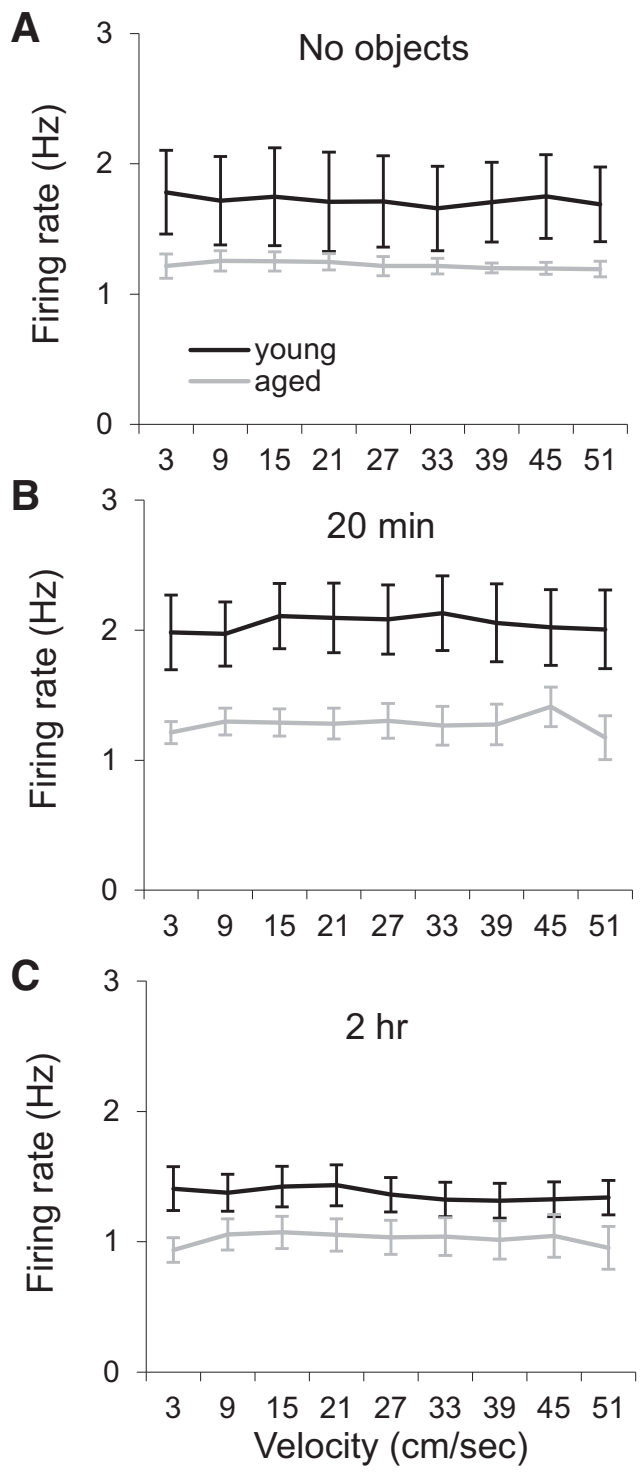

Figure 4. Firing rate by velocity. $\boldsymbol{A}-\boldsymbol{C}$, Mean firing rate was not significantly modulated by velocity in either the young (black) or the aged (gray) rats for the $(\boldsymbol{A})$ no objects-both epochs, $(\boldsymbol{B})$ objects-both epochs with a 20 min delay, and $(\boldsymbol{C})$ objects-both epochs with a $2 \mathrm{~h}$ delay $\left(r_{(53)}<0.1, p>0.5\right.$ for all comparisons; Pearson's correlation coefficient). Error bars represent \pm 1 SEM.

last lap was not significantly different between young and aged rats $\left(F_{(1,10)}=0.20, p=0.66\right.$; repeated-measures ANOVA).

Although the population of recorded PRC neurons did not show a change in firing rate between conditions with novel objects compared with the other behavioral conditions, it is still possible that a subset of PRC neurons might show a response decrement as objects go from being novel to relatively familiar 
and that this decrement was not detected when the data were collapsed across all active neurons. To examine this possibility, PRC neurons that had firing rates at least 2 SDs above mean firing rate during Lap 1 were identified. The proportions of recorded PRC neurons that met this criterion were then compared between the different behavioral conditions and epochs. Approximately $5 \%$ of all the recorded PRC neurons fit this description, but this did not vary significantly between behavioral condition $\left(F_{(15,120)}=1.51, p=0.21\right.$; repeated-measures ANOVA $)$. Moreover, the proportion of cells that showed a response decrement between Lap 1 and the subsequent laps was not significantly different between the young and the aged rats $\left(F_{(1,10)}=3.4, p=\right.$ 0.11 , repeated-measures ANOVA). Figure 5 illustrates the mean proportion of the recorded PRC neurons in young and aged rats during Epochs 1 and 2 that had a firing rate $\geq 2$ SDs above their average firing rate in $(A)$ the no objects-both epochs, $(B)$ the objects-both epochs with a 20 min delay, and $(C)$ the objectsboth epochs with a $2 \mathrm{~h}$ delay. Together, these data indicate no evidence of a response decrement in the activity of PRC neurons as objects went from novel to familiar in either the young or the aged rats.

Similar to previous reports in young rats (Burke et al., 2012a; Deshmukh et al., 2012), when animals traversed the track with objects on it, PRC neurons showed a selective increase in their firing rates at the locations of objects. This occurred when objects were novel (during Epoch 1 of the objects-both epochs conditions), as well as when objects were familiar (during Epoch 2 of the objects-both epochs conditions) in both age groups. Figure 6 shows representative examples of PRC neuron object field activity recorded from young $(A)$ and aged $(B)$ rats.

Placing objects on a track increases the information content of PRC spiking (Burke et al., 2012a), which can be used to quantify the proportion of PRC neurons that increase their firing rate at locations containing objects (see Materials and Methods). Similar to young animals, PRC neurons in both age groups had significantly higher information scores in conditions with objects relative to the no object-both epochs condition $\left(F_{(3,40)}=3.03\right.$, $p<0.05$; repeated-measures ANOVA). The mean information content, however, was significantly reduced in the aged compared with young rats $\left(F_{(1,40)}=8.23, p<0.01\right.$; repeatedmeasures ANOVA) for the conditions with objects $(p<0.5)$, but not for the no objects-both epochs condition ( $p=0.54$; Fig. 7 ). To determine whether the object-related firing properties of PRC cells were present from the very first exposure to objects on the track, the mean information content was calculated and the first behavioral experience with objects in Epoch 1 was compared with the last behavioral experience with objects in Epoch 2. In both the young and the aged rats, there was no difference in the mean information per spike between the first exposure to objects and the last $\left(t_{(11)}=0.41, p=0.69\right.$, paired-samples $t$ test $)$. Because the information scores for the first and last exposure were virtually identical ( $0.58 \mathrm{bits} / \mathrm{spike}$ vs $0.63 \mathrm{bits} / \mathrm{spike})$, it appears that objects on the track increased information content de novo.

The findings that aged PRC principal cell activity patterns show both reduced firing and lower information content during behavior compared with young rats suggests that in advanced age PRC neurons may be less responsive to stimuli. To test this directly, the proportion of neurons with object fields was compared across age groups and behavioral conditions. The young rats had a significantly higher proportion of PRC cells that expressed object fields compared with the aged rats $\left(F_{(1,40)}=44.53, p<0.001\right.$; repeated-measured ANOVA), and this was the case for conditions with objects ( $p<0.05$ for all comparisons; Tukey HSD),
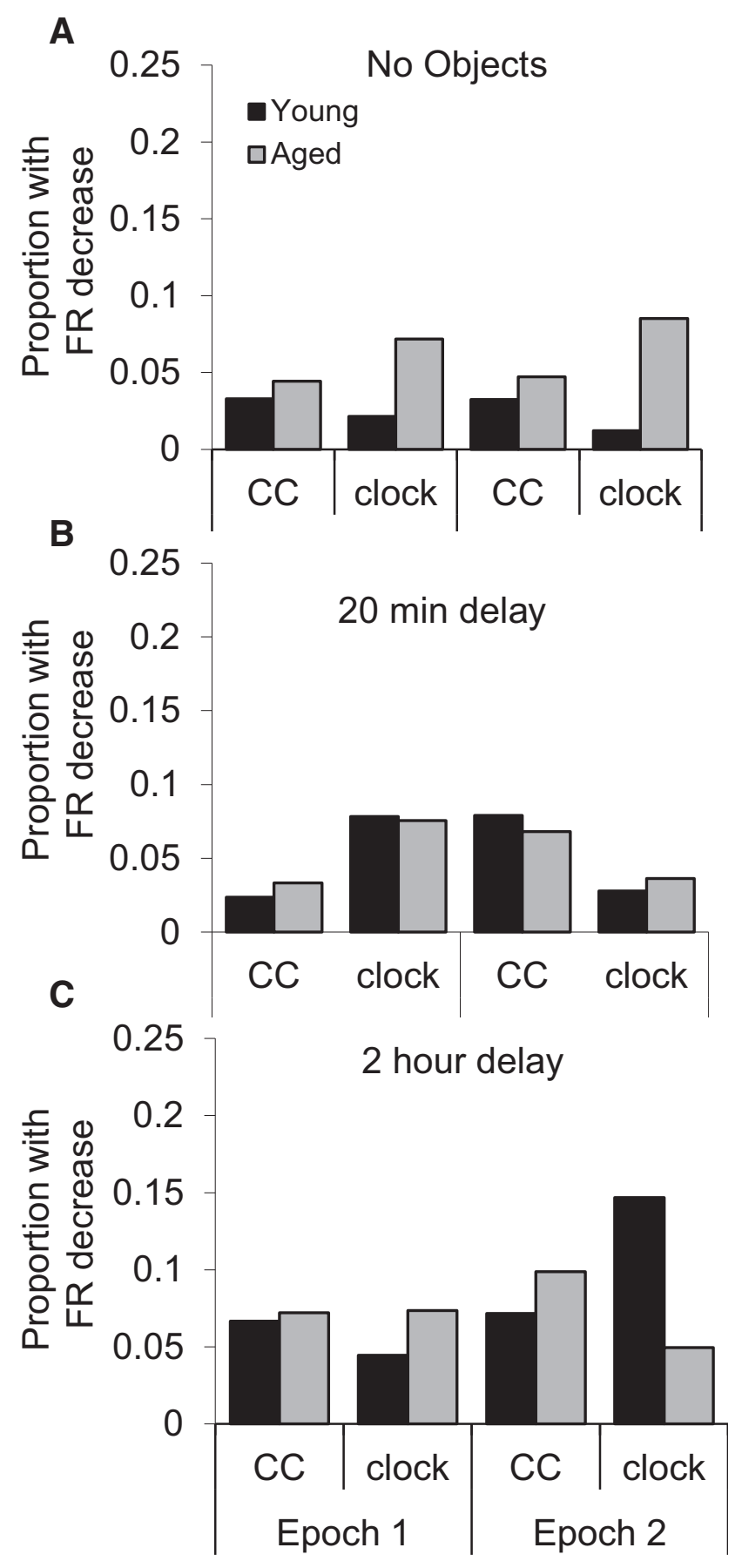

Figure 5. The proportion of recorded PRC neurons that show a response decrement. $A-C$, In both young (black) and aged (gray) rats, no significant difference was found in the proportion of cells that had a response decrement between the $(\boldsymbol{A})$ no objects-both epochs, $(\boldsymbol{B})$ objectsboth epochs with a 20 min delay, and $(C)$ objects- both epochs with a $2 \mathrm{~h}$ delay $\left(F_{(15,120)}=\right.$ $1.51, p=0.21$; repeated-measures ANOVA). Additionally, the young and the aged rats did not differ in the proportion of cells that showed a response decrement between the first lap and subsequent laps $\left(F_{(1,10)}=3.4, p=0.11\right.$, repeated-measures ANOVA). Error bars represent \pm 1 SEM. CC, Counterclockwise running direction; clock, clockwise running direction.

but not for the no objects-both epochs condition $(p=0.12)$. When the age groups were analyzed together, behavioral condition also had a significant effect on the proportion of PRC neurons with object fields $\left(F_{(3,40)}=10.14, p<0.001\right.$; repeated-measures ANOVA). Post hoc comparisons indicated that during the no objects-both epochs condition, significantly fewer neurons met the 

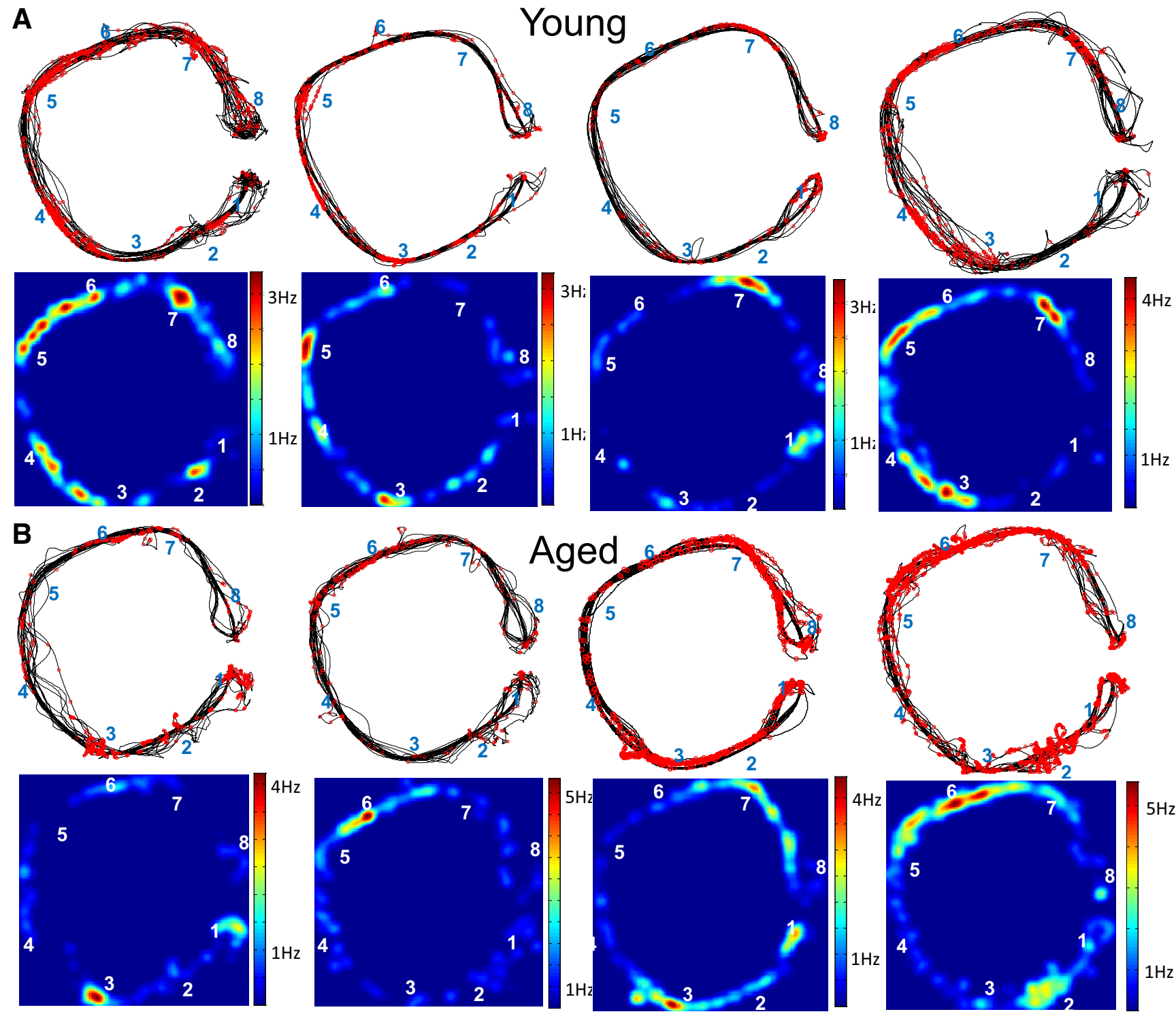

Figure 6. PRC neuron activity patterns in young and aged rats. $A$, The activity of four representative PRC neurons recorded from young rats under conditions with objects on the track. Top, Black trace, Path of the rats. Red spots indicate the locations of spikes. The blue numbers represent the locations of objects. Bottom, Occupancy-normalized firing-rate maps of the cells shown in $\boldsymbol{A}$. $\boldsymbol{B}$, Same as in $\boldsymbol{A}$ for four representative neurons recorded in aged rats. Note the increase in spiking at several of the locations containing objects.

criteria for having object fields relative to behavioral conditions with objects. Importantly, it did not appear that differences between the distributions of neurons recorded from deep versus superficial layers in the two age groups can account for the reduced proportion of PRC cells with object fields. Specifically, for the three rats that had tetrodes in both Layer V and Layers II/III of the PRC, there was no significant difference in the proportion of cells with object fields between the different layers of cortex $\left(t_{(5)}=0.24, p=0.82\right.$; pairedsample $t$ test). Figure $8 A$ shows the mean proportion of PRC neurons that had object fields for the different behavioral conditions. These data indicate that PRC neurons in both young and aged rats show object-related spiking, but that the young rats have a higher proportion of neurons that show object fields.

The age-associated reduction in the proportion of PRC principal cells that expressed object fields cannot account for the lower firing rates of PRC neurons during the no objects-both epochs condition in old compared with young rats, because in this condition the same proportion of neurons in young and old rats met the criteria for having an object field. An alternative explanation for the lower mean firing rates in aged compared with young rats could be an increase in the proportion of cells that fired during both Rest 1 and Rest 3 but did not fire during behavior in old animals. Consistent with this idea is the observation that the proportions of neurons that did not show any activity during an episode of track running (mean firing rate $<0.2$ spikes/occupancy) was significantly higher in the aged compared with the young rats $\left(F_{(1,40)}=34.80, p<0.001\right.$; repeatedmeasures ANOVA; Fig. $8 B$ ). This difference was observed during all behavioral conditions ( $p<0.05$ for all comparisons, Tukey HSD). In both young and old rats, however, there was no significant effect of condition on the proportion of inactive neurons $\left(F_{(3,40)}=0.82, p=0.49\right.$; repeated-measures ANOVA; Fig. $\left.8 B\right)$. Because the proportion of object fields significantly increases in the object condition, and there is no difference across conditions in number of inactive cells, it does not appear that the "quiet neurons" were the cells that acquired objects fields. 


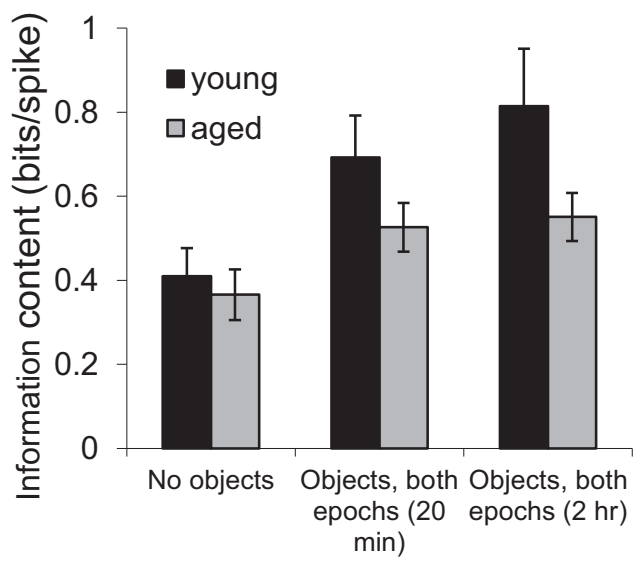

Figure 7. PRC neuron information content. The mean information content ( $y$-axis) of the PRC neurons that showed activity during track running for the young (black) and aged (gray) rats in the different behavioral conditions. There was a significant effect of behavioral condition $\left(F_{(3,40)}=3.03, p<0.05\right.$; repeated-measures ANOVA $)$ and age $\left(F_{(1,40)}=8.23, p<0.01\right.$; repeated-measures ANOVA) on the information content of PRC principal cell firing. Young and old rats did not differ in the no object condition, but young rats had significantly higher information content in the object conditions. Error bars represent \pm 1 SEM.

Figure $8 C$ shows the proportions of neurons that showed nonselective activity (mean firing rate $>0.2$ spikes/occupancy but no object field) on the track during the four different behavioral conditions. There was a significant effect of condition on the proportion of neurons with nonselective spiking on the track $\left(F_{(3,40)}=15.14, p<0.001\right.$; repeated-measures ANOVA). Specifically, in both young and aged rats, significantly more PRC neurons showed nonselective activity on the track during the no objects conditions relative to the conditions with objects $(p<0.5$ for all comparisons). These data indicate that it is the neurons with nonselective activity on the track that will potentially develop object fields when stimuli are added to the track. Thus, it is possible that a level of baseline activity prepares a portion of the PRC neuron population to respond when a salient feature is encountered in an environment.

Age also significantly affected the proportion of neurons with nonselective spiking on the track $\left(F_{(1,40)}=7.30, p<0.01\right.$; repeated-measures ANOVA). Specifically, the young rats had a significantly larger proportion of nonselective neurons, relative to the aged rats, during the no objects condition $\left(t_{(11)}=4.10, p<\right.$ 0.01 ; paired-samples $t$ test), but not during conditions with objects ( $p>0.4$ for all comparisons). Interestingly, there was an $\sim 17 \%$ reduction in the proportion of nonselective neurons between the young and aged rats. This is comparable to the $\sim 14 \%$ reduction in the proportion of neurons expressing object fields between the young and old animals. Thus, it is possible that the old rats have fewer neurons with object fields because initially, under conditions without objects, they have a smaller pool of neurons that are prepared to show selective spiking when salient features are added to an environment.

To test this idea directly, PRC neurons were recorded during two control conditions: no objects-objects and objects-no objects. This enabled the effects of objects to be measured on the same population of PRC neurons. Figure $9 A-D$ shows a representative example of nonspecific activity of PRC neurons when no objects are on the track (left) that then express object fields when objects are on the track (right) in a young (top) and an aged rat (bottom). The patterns of firing in Figure $9 A, C$ lend further
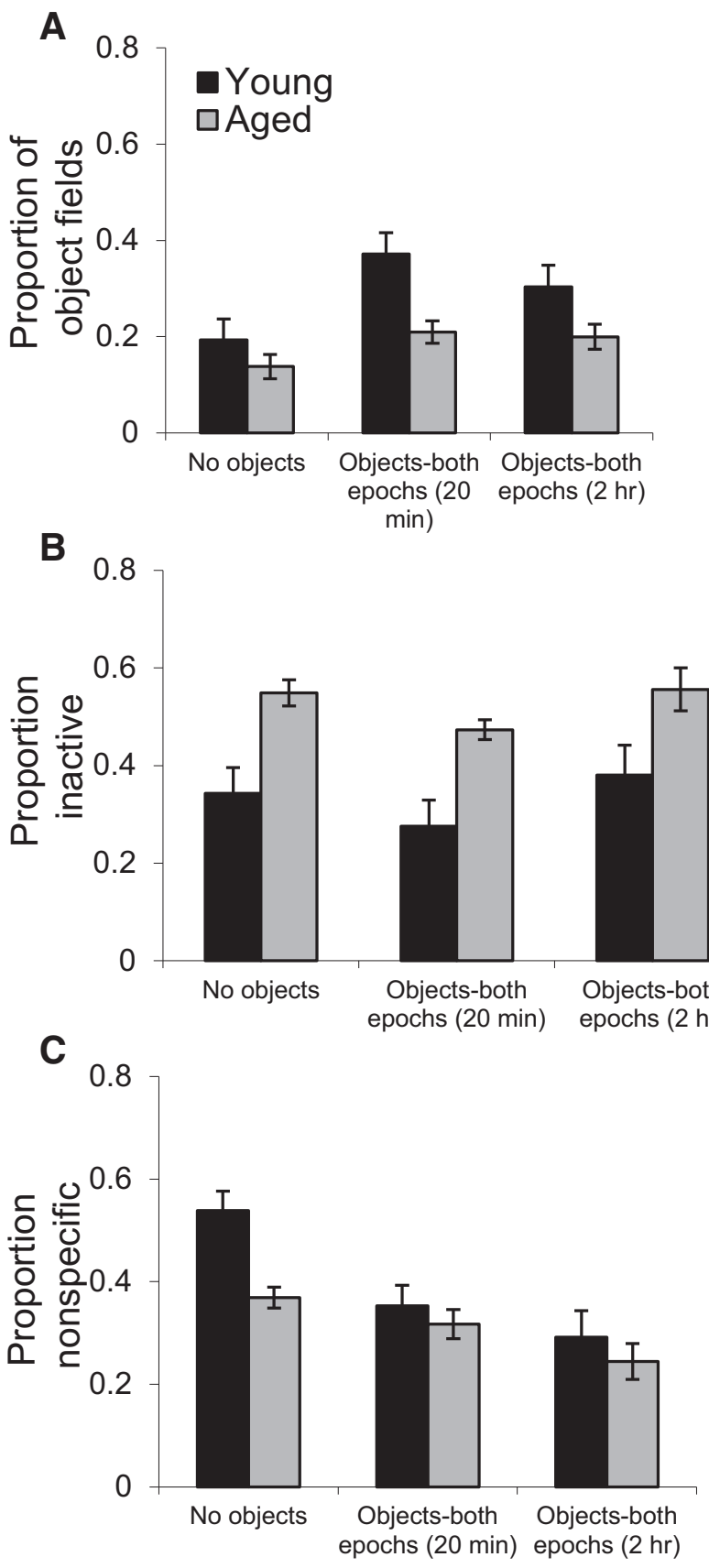

Figure 8. Proportion of PRC neurons with object fields, no firing, or nonselective firing during behavior. $\boldsymbol{A}$, The proportion of PRC neurons with object fields ( $y$-axis) in young (black) and aged (gray) rats across the different behavior conditions ( $x$-axis). The young rats had significantly more cells with object fields relative to the aged animals for the objects- both epochs with a 20 min delay $\left(t_{(11)}=3.50, p<0.01\right.$; paired-samples $t$ test), and the objects-both epochs with a $2 \mathrm{~h}$ delay $\left(t_{(9)}=3.26, p<0.05\right.$; paired-samples $t$ test). $\boldsymbol{B}$, The proportion of PRC neurons that fired during rest, but did not show activity during behavior in young (black) and aged (gray) rats. Across all behavioral conditions, significantly more PRC neurons were inactive during track running in the aged compared with the young rats $\left(F_{(1,40)}=34.80, p<0.001\right.$; repeated-measures ANOVA). $\boldsymbol{C}$, The proportions of neurons that were active on the maze but did not show selective spiking at an object location were significantly greater for the no objects condition relative to the conditions with objects ( $p<0.05$ for all comparisons). Aged rats showed significantly fewer neurons with nonselective activity on the track relative to the young rats during the no objects conditions $\left(t_{(11)}=4.10, p<0.01\right.$; paired-samples $t$ test), but not during conditions with objects ( $p>0.1$ for all comparisons). Error bars are \pm 1 SEM. 
A

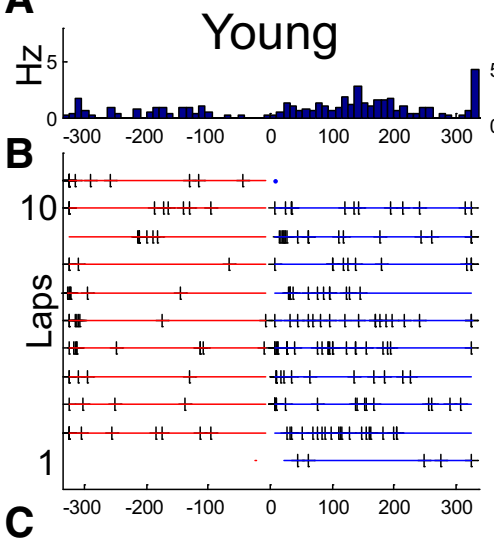

$\mathbf{E}$
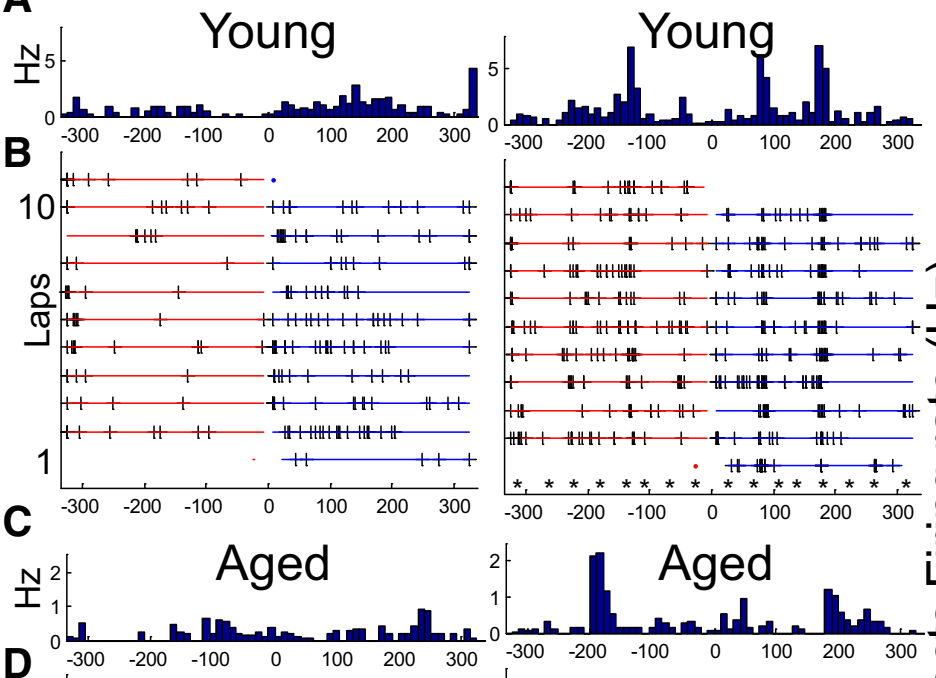

i⿳亠二口犬

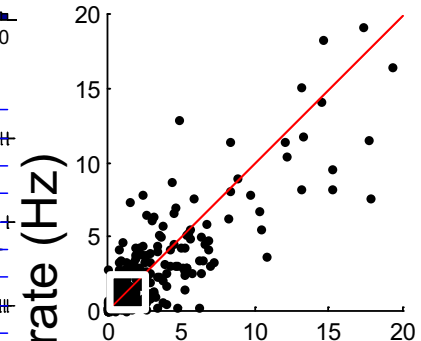

$5 \quad 10 \quad 15 \quad 20$

Young

No objects Firing rate $(\mathrm{Hz})$

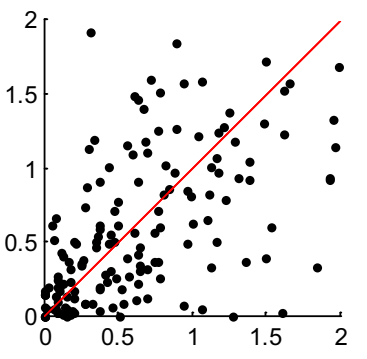

Aged
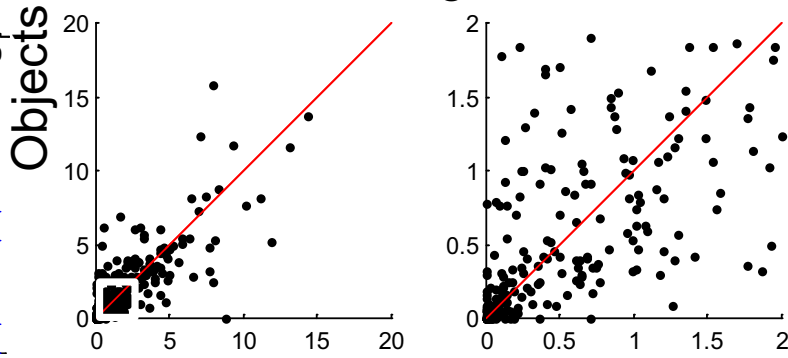

No objects Firing rate $(\mathrm{Hz})$

Figure 9. Perirhinal cortical neuron activity in the no object- object condition. $\boldsymbol{A}-\boldsymbol{D}$, The firing patterns for a representative PRC neuron from a young $(\boldsymbol{A}, \boldsymbol{B})$ and an aged $(\boldsymbol{C}, \boldsymbol{D})$ rat during Epoch 1 without objects (left) and Epoch 2 (right) in which the track contained objects. The activity from the same cells are shown in the left and right panels. The firing-rate histogram by "linearized" position is shown in $\boldsymbol{A}$ for young rats and $\boldsymbol{C}$ for aged rats. The $\boldsymbol{x}$-axis is positioned on the track with zero indicating the position of the barrier. Distance from the barrier is measures in centimeters. Positive numbers are for laps when the rat was running in the clockwise direction while negative numbers indicate the position when the rat was running in the counterclockwise direction. The $y$-axis is the occupancy-normalized firing rate of the neuron. Spike raster plots across laps are shown in $\boldsymbol{B}$ for young rats and in $\boldsymbol{D}$ for aged rats. Each horizontal line indicates a lap and blue lines are the laps in which the rat ran in the counterclockwise direction while red lines represent laps run in the clockwise direction. The asterisks indicate the position of the objects. In both the young and aged rat, there was nonspecific activity during the first epoch and significant object field firing during the second epoch. $\boldsymbol{E}$, The firing rates of individual neurons during the no objects epoch plotted against the firing rates during the epoch with objects for young (top) and aged (bottom) rats. The left panels show all cells and the right panels show only those cells from the left panels that have firing rates of $\angle 2 \mathrm{~Hz}$ (white square in left panels). Note, the higher density of low firing-rate cells in the aged rats. There was a significant correlation between firing rate across epochs with and without objects $\left(R^{2}=0.79, F_{(3,23)}=24.32, p<0.001\right)$. Age of the animal $\left(t_{(23)}=0.25, p=0.81\right)$ and whether the track contained objects during the first or second epoch $\left(t_{(23)}=0.54, p=0.53\right)$ did not significantly affect this relationship.

support to the hypothesis that it is the cells with nonspecific activity that are primed to express object fields. In line with this idea, within the same population of cells, placing objects on the track did not significantly affect firing rate $\left(F_{(1,20)}=0.41, p=\right.$ 0.53 ; repeated measures) or the proportion of cells that did not fire during behavior $\left(F_{(1,20)}=2.56, p=0.12\right.$; repeated measures). Figure $9 E$ shows the firing rates of neurons during the no objects epochs plotted against the firing rates during the epochs with objects for young (top) and aged (bottom) rats. It is evident from Figure $9 E$ that there was no cluster of cells above unity. Therefore, the "quiet" neurons during the no objects epoch also do not fire when objects are on the track. Moreover, there was a significant correlation between firing rates across the no object and object epochs $\left(R^{2}=0.79, F_{(3,23)}=24.32, p<0.001\right)$. Age of the animal did not significantly affect this relationship $\left(_{(23)}=0.25, p=\right.$ $0.81)$. These data lend further support to the idea that objects adjust the spike timing of PRC neurons rather than increasing overall excitability levels.

In both young and aged rats, within the same population of cells, the PRC neurons recorded during the epochs with objects had significantly higher information content $\left(F_{(1,20)}=17.78, p<\right.$
0.001; repeated measures) and a significantly higher proportion of cells that met the criteria for having an object field $\left(F_{(1,20)}=\right.$ $21.62, p<0.001$; repeated measures) compared with the epochs when the track was empty. When the aged groups were examined separately, consistent with the data collected during the no objects-both epochs and objects-both epochs conditions, the aged rats had a significantly lower proportion of PRC cells that expressed object fields when objects were on the track relative to the young animals $\left(F_{(1,20)}=4.52, p<0.05\right.$; repeated measures $)$. Moreover, similar to the other behavioral conditions, the mean firing rate of PRC neurons was significantly lower in the aged compared with the young rats $\left(F_{(1,22)}=5.57, p<0.05\right.$; repeated measures). Therefore, in old rats, when three-dimensional stimuli are added to the track, there are fewer neurons primed to respond to objects, which results in a lower proportion of cells with object fields. This is consistent with the hypothesis that PRC-dependent stimulus representation is impaired in advanced age.

Perirhinal cortical activity across delays

To evaluate whether PRC neuron activity patterns were similar between epochs, the correlation of PRC neuron firing-rate vec- 


\section{A}
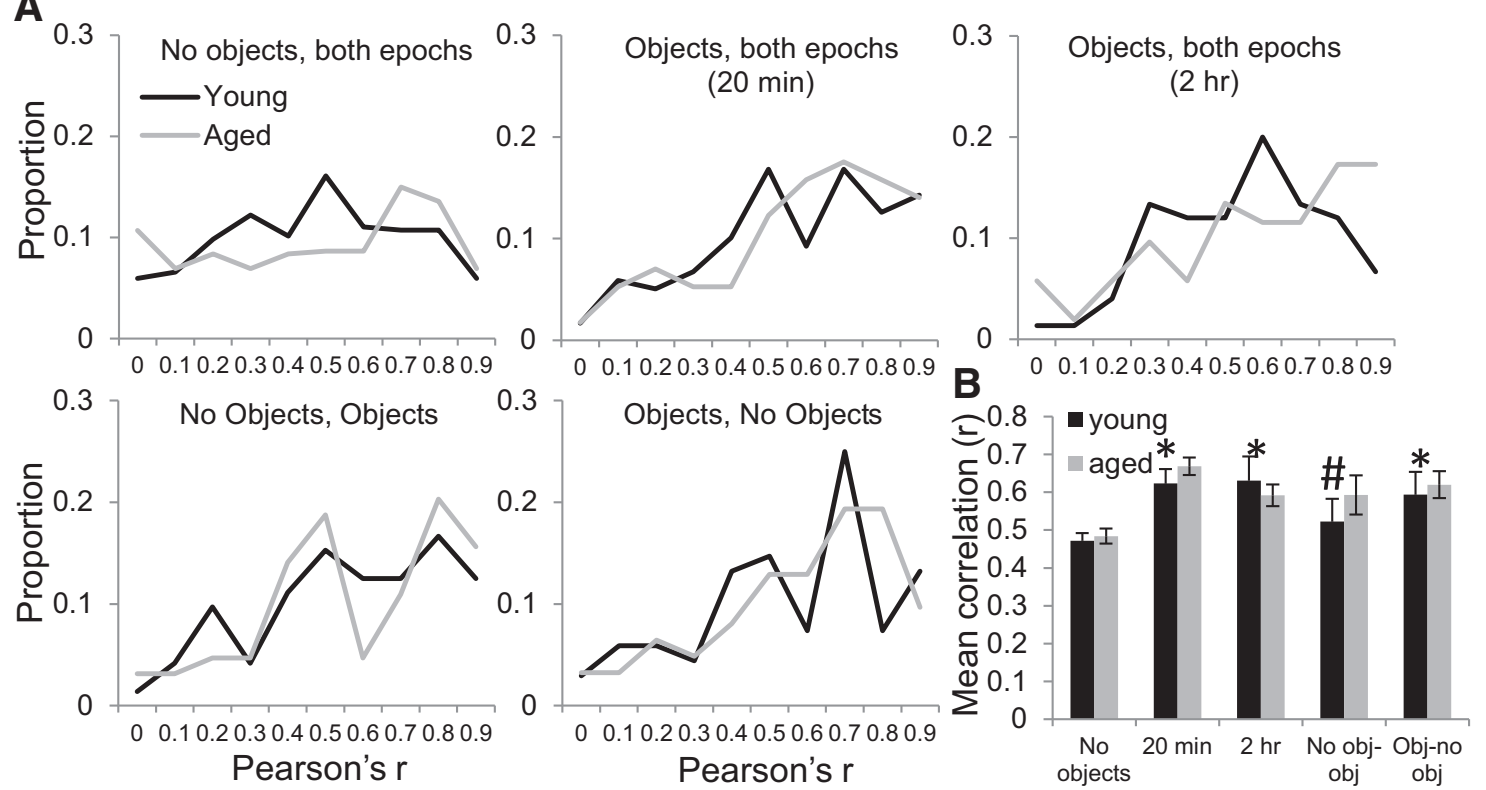

Figure 10. Activity pattern correlations across epochs. $\boldsymbol{A}$, The normalized frequency histograms of the Pearson's correlation coefficients of the activity during Epoch 1 and Epoch 2 for the different behavioral conditions. $\boldsymbol{B}$, The mean correlation values averaged across rats. Behavioral condition had a significant effect on the correlated activity $\left(F_{(5,45)}=49.32, p<0.001\right.$; repeated measures). Planned orthogonal contrasts revealed that the mean correlation values of PRC neuron activity across epochs was significantly less for the no objects- both epochs condition relative to the conditions with objects during both epochs, and the objects-no objects control condition (indicated by ${ }^{*} p<0.01$ for all comparisons; simple contrast). The no objects- objects conditions was significantly less correlated than the 20 min delay condition (indicated by ${ }^{\#} p<0.05$; simple contrast). Age group did not have a significant effect on correlated activity patterns $\left(F_{(1,9)}=1.02, p=0.34 ;\right.$ repeated measures).

tors between Epoch 1 and Epoch 2 was calculated for the different behavioral conditions. Figure $10 \mathrm{~A}$ shows the normalized frequency histograms of the Pearson's correlation coefficients between Epoch 1 and Epoch 2 activity patterns for the different behavioral conditions in young (black) and aged (gray) rats, and Figure $10 B$ shows the mean correlation values averaged across rats. Behavioral condition had a significant effect on the correlation values $\left(F_{(5,45)}=49.32, p<0.001\right.$; repeated measures $)$ such that the PRC neuron activity correlations between epochs were significantly lower for the no objects-both epochs condition relative to the conditions with objects during both epochs (20 min and 2 h delays; $p<0.01$ for both comparisons; simple contrast). Together these data indicate that, contrary to object-related firing, the nonspecific activity is not spatially consistent across delays. Additionally, the between-epoch correlations for the no objects-both epochs condition was not significantly different from the no objects-objects control condition $(p=0.1$; simple contrast), but was significantly lower than the objects-no objects condition ( $p<0.01$; simple contrast). This suggests that some PRC neurons may show persistent object-related activity even after the stimulus has been removed, which has been reported for a small subset of lateral entorhinal cortical neurons (Deshmukh and Knierim, 2011; Tsao et al., 2013).

Importantly, age group did not have a significant effect on the extent of correlated activity patterns $\left(F_{(1,9)}=1.02, p=0.34\right.$; repeated measures). Moreover, age group did not significantly interact with behavioral condition $\left(F_{(5,45)}=0.47, p=0.79\right.$; repeated measures), which indicates that the correlated activity patterns of PRC neurons across behavioral epochs did not vary between young and old rats as a function of experience with the objects. These data are consistent with the observation that old animals are able to identify previously experienced objects as familiar within the same environment for delays up to $24 \mathrm{~h}$ (Burke et al., 2010). Age also did not significantly affect rate re- mapping (data not shown). Together these data indicate that aged rats have fewer cells that are active in the presence of objects. Once the representations of complex stimuli are established within the PRC, however, the aged rats are just as able to maintain stable activity patterns in response to familiar stimuli for delays up to $2 \mathrm{~h}$.

\section{Discussion}

\section{Object fields in young and aged rats}

The current experiments provide evidence that old animals have selective impairments in stimulus representation rather than deficits in stimulus maintenance. Compared with the young rats, the aged rats had a lower proportion of neurons with object fields and a higher proportion of neurons that were inactive during track running. Interestingly, in both age groups, the proportion of inactive neurons were similar between conditions with and without objects. Thus, it appears that the neurons with nonselective activity were the subset of PRC cells that developed object fields. This is supported by the observed reduction in the proportion of neurons with nonselective activity in the object conditions and the lack of a significant firing rate change between object and no object conditions.

Together these data support two novel hypotheses regarding PRC function. First, it appears that when the track was relatively empty, a subset of PRC neurons express baseline activity with no obvious pattern. This activity could reflect circuit dynamics that predispose specific neurons to sharpen their tuning to track location when a salient feature is encountered. Second, with respect to aged rats, the decreased numbers of neurons showing nonselective activity on the empty track could arise from a loss of fidelity in the afferent input to the aged PRC. The PRC receives direct projections from the entire sensory cortex (Burwell and Amaral, 1998). With advanced age, there are disruptions in cortical inhibition in the auditory (de Villers-Sidani et al., 2010), so- 
matosensory (David-Jürgens and Dinse, 2010), and visual cortices (Wang et al., 2006). This has been associated with declines in signal-to-noise ratios that could feed forward to the PRC, resulting in reduced convergence of input needed to elicit spiking. Alternatively, lower firing rates in aged PRC neurons during behavior could serve as a compensatory mechanism for disrupted inhibition at earlier stages of cortical processing. Both of these hypotheses are consistent with the observation that glutamate levels are reduced in the aged PRC (Liu et al., 2009) and with the report of reduced BOLD signal in the PRC of elderly subjects (Ryan et al., 2012).

A question remains regarding the function of PRC neurons that do not show activity under the behavior conditions of the current experiment. One possibility is that these "quiet neurons" will only become active when the animal encounters a stimulus that is emotionally salient or relevant for its survival. In line with this hypothesis is the observation that more PRC neurons respond selectively to an auditory cue after it has been paired with a foot shock (Furtak et al., 2007). Under this framework, the quiet neurons are those that require extra activation, presumably through direct basolateral amygdala (Paz et al., 2006) or prefrontal cortical input (Paz et al., 2007), to be recruited into the ensemble of active PRC neurons.

\section{The lack of novelty and/or familiarity modulation of perirhinal cortical neuron activity in young and aged rats} A prevailing theory regarding the neurobiology of recognition memory is that the mnemonic mechanism for this behavior is a reduction in the firing rate of PRC neurons as a stimulus goes from novel to familiar (for review, see Brown and Aggleton, 2001). The results reported in the current paper along with additional recent data, however, have been unable to provide support for this idea. Specifically, monkeys performing a passive viewing task with pictures of varying levels of novelty or familiarity do not show robust firing-rate differences in principal cell activity as a function of familiarity (Thome et al., 2012; Woloszyn and Sheinberg, 2012). Moreover, another recent investigation observed no change in the proportion of PRC neurons positive for the mRNA products of the activity-associated immediate-early gene (IEG) Arc as objects went from novel to familiar (Burke et al., 2012b).

Several possible explanations can account for the discrepancy between different experiments regarding the effect of stimulus familiarity on PRC activity. In terms of the effect of novelty versus familiarity on IEG expression in the PRC, it is known that IEG expression can be decoupled from neuronal activity after a massed exposure to an environment (Guzowski et al., 2006). The paired viewing procedure used in c-fos imaging studies involved presenting rats with the same visual stimuli many times in a day over the course of several days (Wan et al., 1999). Therefore, it remains a possibility that the $\mathrm{PRC}$ shows reduced $\mathrm{c}$-fos protein levels because of a post-translational decoupling from spiking activity rather than reduced neuron activity.

One explanation of the apparently contradictory reports of reduced PRC firing rates in other electrophysiological recording experiments (Miller et al., 1991; Fahy et al., 1993; Hölscher et al., 2003) could involve the fact that in these studies acute recording techniques were used. It is possible that during acute recordings there is a sampling bias for cells with higher firing rates, and these cells may be more likely to decrease their rate over time. Investigations that have not observed novelty modulation of PRC neuron firing rates have used chronically implanted recording probes (Burke et al., 2012a; Thome et al., 2012). Another, but not mu-

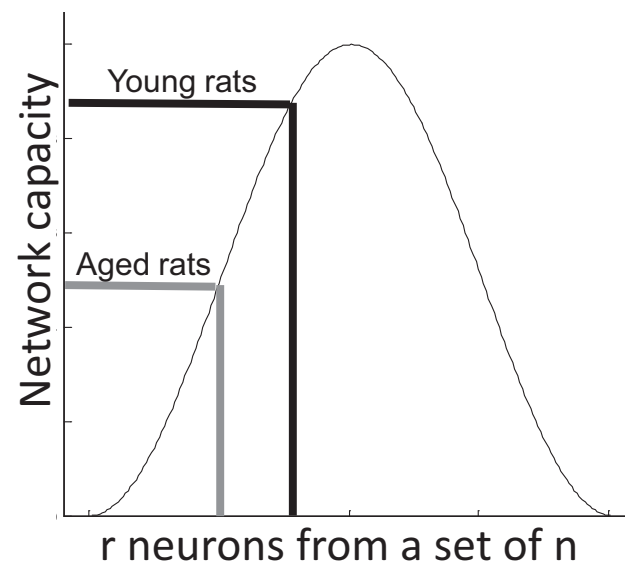

Figure 11. Population coding in the PRC. The capacity of a hypothetical network to represent distinct stimuli based on the degree to which the population code is distributed. The $x$-axis is the number of neurons $(r)$ in a set of $n$ neurons. Network capacity is maximal when half of the neurons are activated by a given stimulus set. In the PRC cortex, fewer neurons are activated by a stimulus set in aged (gray) compared with young (black) rats. This could have the result of decreasing the capacity of the aged PRC to represent different stimuli distinctively.

tually exclusive, explanation is that most of the initial reports of reduced PRC cell firing to familiar stimuli did not isolate interneurons from principal cells. Recent data suggest that it may be the interneurons of the inferior temporal cortex, rather than excitatory cells, that show reduced activity to familiar versus novel stimuli (Woloszyn and Sheinberg, 2012).

Lesion data are unequivocal concerning the fact the PRC is critical for stimulus recognition (Ennaceur and Aggleton, 1997; Málková et al., 2001; Winters and Bussey, 2005). In light of the current results, the notion that a simple rate code supports recognition may not be parsimonious. In fact, a rate code is vulnerable to noise and spike failures. Given that the probability of synaptic transmission between the PRC and its cortical efferents is low (Pelletier et al., 2004), the signal-to-noise ratio for relaying a "response decrement" might not be sufficient. Thus, it is more plausible that the PRC uses a population code, which relies on the joint activities of a number of neurons, each of which has a different distribution of responses over some set of inputs (Georgopoulos et al., 1986).

\section{Linking physiology to age-associated recognition memory impairments}

Recent data have revealed that age-associated recognition memory impairments arise from aged animals "falsely" recognizing novel stimuli (Burke et al., 2010). It has been hypothesized that this results from old animals showing an increased vulnerability to distracting stimuli encountered during long delays (Burke et al., 2010). Importantly, animals with PRC lesions show the same pattern of results, and the tendency to falsely remember a novel stimulus can be reversed by depriving lesioned animals of sensory input during the delay period (McTighe et al., 2010). These data imply that recognition memory deficits in animals with a compromised PRC are not due to the "forgetting" of previously experienced stimuli, but rather manifests from a reduced ability to discriminate novel stimuli from those that have been experienced (Burke et al., 2010; McTighe et al., 2010). This type of discrimination deficit could arise from impairments in high-level stimulus perception that arise following damage to the PRC (Murray and Bussey, 1999; Murray et al., 2007), because of a reduced ability to pattern separate between stimuli that share features. In 
line with this idea is the observation that aged rats, monkeys (Burke et al., 2011), and humans (Ryan et al., 2012) have difficulty discriminating between complex stimuli that share features even when the mnemonic demands of the task are low.

In line with the behavioral observations discussed above, the physiological data reported here suggest that aged animals do not forget previously experienced stimuli. That is, the older rats' PRC neurons show the same levels of correlated activity across delays up to $2 \mathrm{~h}$. Aged rats, however, appear to have a reduced pool of active PRC neurons available and prepared to represent new stimulus sets. Figure 11 shows how the capacity of a theoretical network is affected by increasing or decreasing the number of neurons that are active when a stimulus set is presented. The theoretical functional consequence of fewer neurons being activated by objects is reduced capacity to represent different objects with a unique neural code. This could explain why aged rats tend to regard novel objects as familiar (Burke et al., 2010).

An assumption regarding the cognitive consequences of normal aging is that the aspect of recognition memory supported by PRC-dependent familiarity judgments is preserved across the lifespan, while recollection is particularly vulnerable (Spencer and Raz, 1995; Daselaar et al., 2006). This hypothesis, however, may not be consistent with the observation that aged subjects show a significant increase in false recognition (Norman and Schacter, 1997; Jacoby et al., 2005; Toner et al., 2009). Moreover, other investigations have reported that aging is associated with deficits in familiarity as well as recollective processes (Davidson and Glisky, 2002; Prull et al., 2006; Toth and Parks, 2006; Duarte et al., 2010). These data, along with the current findings, call into question the notion that recollection is particularly vulnerable to advanced age in the absence of changes in familiarity. In fact it is probable that degradation of PRC-dependent stimulus representation contributes to impairments in recollection and episodic memory, both of which require the association of sensory stimuli with a spatial and temporal context.

\section{References}

Barnes CA, Rao G, McNaughton BL (1996) Functional integrity of NMDAdependent LTP induction mechanisms across the lifespan of F-344 rats. Learn Mem 3:124-137. CrossRef Medline

Barthó P, Hirase H, Monconduit L, Zugaro M, Harris KD, Buzsáki G (2004) Characterization of neocortical principal cells and interneurons by network interactions and extracellular features. J Neurophysiol 92:600-608. CrossRef Medline

Brown MW, Aggleton JP (2001) Recognition memory: what are the roles of the perirhinal cortex and hippocampus? Nat Rev Neurosci 2:51-61. CrossRef Medline

Bucci DJ, Phillips RG, Burwell RD (2000) Contributions of postrhinal and perirhinal cortex to contextual information processing. Behav Neurosci 114:882-894. CrossRef Medline

Burke SN, Wallace JL, Nematollahi S, Uprety AR, Barnes CA (2010) Pattern separation deficits may contribute to age-associated recognition impairments. Behav Neurosci 124:559-573. CrossRef Medline

Burke SN, Wallace JL, Hartzell AL, Nematollahi S, Plange K, Barnes CA (2011) Age-associated deficits in pattern separation functions of the perirhinal cortex: a cross-species consensus. Behav Neurosci 125:836847. CrossRef Medline

Burke SN, Maurer AP, Hartzell AL, Nematollahi S, Uprety A, Wallace JL, Barnes CA (2012a) Representation of three-dimensional objects by the rat perirhinal cortex. Hippocampus 22:2032-2044. CrossRef Medline

Burke SN, Hartzell AL, Lister JP, Hoang LT, Barnes CA (2012b) Layer V perirhinal cortical ensemble activity during object exploration: a comparison between young and aged rats. Hippocampus 22:2080-2093. CrossRef Medline

Burwell RD, Amaral DG (1998) Cortical afferents of the perirhinal, postrhinal, and entorhinal cortices of the rat. J Comp Neurol 398:179-205. CrossRef Medline
Chowdhury S, Shepherd JD, Okuno H, Lyford G, Petralia RS, Plath N, Kuhl D, Huganir RL, Worley PF (2006) Arc/Arg3.1 interacts with the endocytic machinery to regulate AMPA receptor trafficking. Neuron 52:445459. CrossRef Medline

Daselaar SM, Fleck MS, Dobbins IG, Madden DJ, Cabeza R (2006) Effects of healthy aging on hippocampal and rhinal memory functions: an eventrelated fMRI study. Cereb Cortex 16:1771-1782. Medline

David-Jürgens M, Dinse HR (2010) Effects of aging on paired-pulse behavior of rat somatosensory cortical neurons. Cereb Cortex 20:1208-1216. CrossRef Medline

Davidson PS, Glisky EL (2002) Neuropsychological correlates of recollection and familiarity in normal aging. Cogn Affect Behav Neurosci 2:174186. CrossRef Medline

Deshmukh SS, Knierim JJ (2011) Representation of non-spatial and spatial information in the lateral entorhinal cortex. Front Behav Neurosci 5:69. CrossRef Medline

Deshmukh SS, Johnson JL, Knierim JJ (2012) Perirhinal cortex represents nonspatial, but not spatial, information in rats foraging in the presence of objects: comparison with lateral entorhinal cortex. Hippocampus 22: 2045-2058. CrossRef Medline

de Villers-Sidani E, Alzghoul L, Zhou X, Simpson KL, Lin RC, Merzenich MM (2010) Recovery of functional and structural age-related changes in the rat primary auditory cortex with operant training. Proc Natl Acad Sci U S A 107:13900-13905. CrossRef Medline

Duarte A, Graham KS, Henson RN (2010) Age-related changes in neural activity associated with familiarity, recollection and false recognition. Neurobiol Aging 31:1814-1830. CrossRef Medline

Ennaceur A, Aggleton JP (1997) The effects of neurotoxic lesions of the perirhinal cortex combined to fornix transection on object recognition memory in the rat. Behav Brain Res 88:181-193. CrossRef Medline

Ennaceur A, Delacour J (1988) A new one-trial test for neurobiological studies of memory in rats. 1: behavioral data. Behav Brain Res 31:47-59. CrossRef Medline

Fahy FL, Riches IP, Brown MW (1993) Neuronal activity related to visual recognition memory: long-term memory and the encoding of recency and familiarity information in the primate anterior and medial inferior temporal and rhinal cortex. Exp Brain Res 96:457-472. Medline

Fletcher BR, Calhoun ME, Rapp PR, Shapiro ML (2006) Fornix lesions decouple the induction of hippocampal arc transcription from behavior but not plasticity. J Neurosci 26:1507-1515. CrossRef Medline

Furtak SC, Allen TA, Brown TH (2007) Single-unit firing in rat perirhinal cortex caused by fear conditioning to arbitrary and ecological stimuli. J Neurosci 27:12277-12291. CrossRef Medline

Gage GJ, Kipke DR, Shain W (2012) Whole animal perfusion fixation for rodents. J Vis Exp 65:3564. CrossRef Medline

Gallagher M, Burwell R, Burchinal M (1993) Severity of spatial learning impairment in aging: development of a learning index for performance in the Morris water maze. Behav Neurosci 107:618-626. CrossRef Medline

Georgopoulos AP, Schwartz AB, Kettner RE (1986) Neuronal population coding of movement direction. Science 233:1416-1419. CrossRef Medline

Gothard KM, Skaggs WE, Moore KM, McNaughton BL (1996) Binding of hippocampal CA1 neural activity to multiple reference frames in a landmark-based navigation task. J Neurosci 16:823-835. Medline

Guzowski JF, Lyford GL, Stevenson GD, Houston FP, McGaugh JL, Worley PF, Barnes CA (2000) Inhibition of activity-dependent arc protein expression in the rat hippocampus impairs the maintenance of long-term potentiation and the consolidation of long-term memory. J Neurosci 20:3993-4001. Medline

Guzowski JF, Miyashita T, Chawla MK, Sanderson J, Maes LI, Houston FP, Lipa P, McNaughton BL, Worley PF, Barnes CA (2006) Recent behavioral history modifies coupling between cell activity and Arc gene transcription in hippocampal CA1 neurons. Proc Natl Acad Sci U S A 103: 1077-1082. CrossRef Medline

Harris KD, Hirase H, Leinekugel X, Henze DA, Buzsáki G (2001) Temporal interaction between single spikes and complex spike bursts in hippocampal pyramidal cells. Neuron 32:141-149. CrossRef Medline

Higuchi S, Miyashita Y (1996) Formation of mnemonic neuronal responses to visual paired associates in inferotemporal cortex is impaired by perirhinal and entorhinal lesions. Proc Natl Acad Sci U S A 93:739-743. CrossRef Medline

Hölscher C, Rolls ET, Xiang J (2003) Perirhinal cortex neuronal activity 
related to long-term familiarity memory in the macaque. Eur J Neurosci 18:2037-2046. CrossRef Medline

Insel N, Patron LA, Hoang LT, Nematollahi S, Schimanski LA, Lipa P, Barnes CA (2012) Reduced gamma frequency in the medial frontal cortex of aged rats during behavior and rest: implications for age-related behavioral slowing. J Neurosci 32:16331-16344. CrossRef Medline

Jacoby LL, Bishara AJ, Hessels S, Toth JP (2005) Aging, subjective experience, and cognitive control: dramatic false remembering by older adults. J Exp Psychol Gen 134:131-148. CrossRef Medline

Kholodar-Smith DB, Allen TA, Brown TH (2008) Fear conditioning to discontinuous auditory cues requires perirhinal cortical function. Behav Neurosci 122:1178-1185. CrossRef Medline

Liu P, Smith PF, Darlington CL (2008) Glutamate receptor subunits expression in memory-associated brain structures: regional variations and effects of aging. Synapse 62:834-841. CrossRef Medline

Liu P, Jing Y, Zhang H (2009) Age-related changes in arginine and its metabolites in memory-associated brain structures. Neuroscience 164:611628. CrossRef Medline

Málková L, Bachevalier J, Mishkin M, Saunders RC (2001) Neurotoxic lesions of perirhinal cortex impair visual recognition memory in rhesus monkeys. Neuroreport 12:1913-1917. CrossRef Medline

Maurer AP, Vanrhoads SR, Sutherland GR, Lipa P, McNaughton BL (2005) Self-motion and the origin of differential spatial scaling along the septotemporal axis of the hippocampus. Hippocampus 15:841-852. CrossRef Medline

McNaughton BL, Barnes CA, O'Keefe J (1983a) The contributions of position, direction, and velocity to single unit activity in the hippocampus of freely-moving rats. Exp Brain Res 52:41-49. Medline

McNaughton BL, O'Keefe J, Barnes CA (1983b) The stereotrode: a new technique for simultaneous isolation of several single units in the central nervous system from multiple unit records. J Neurosci Methods 8:391397. CrossRef Medline

McTighe SM, Cowell RA, Winters BD, Bussey TJ, Saksida LM (2010) Paradoxical false memory for objects after brain damage. Science 330:14081410. CrossRef Medline

Miller EK, Li L, Desimone R (1991) A neural mechanism for working and recognition memory in inferior temporal cortex. Science 254:1377-1379. CrossRef Medline

Morris R (1984) Developments of a water-maze procedure for studying spatial learning in the rat. J Neurosci Methods 11:47-60. CrossRef Medline

Moyer JR Jr, Furtak SC, McGann JP, Brown TH (2011) Aging-related changes in calcium-binding proteins in rat perirhinal cortex. Neurobiol Aging 32:1693-1706. CrossRef Medline

Murray EA, Bussey TJ (1999) Perceptual-mnemonic functions of the perirhinal cortex. Trends Cogn Sci 3:142-151. CrossRef Medline

Murray EA, Wise SP (2012) Why is there a special issue on perirhinal cortex in a journal called Hippocampus? The perirhinal cortex in historical perspective. Hippocampus 22:1941-1951. CrossRef Medline

Murray EA, Bussey TJ, Saksida LM (2007) Visual perception and memory: a new view of medial temporal lobe function in primates and rodents. Annu Rev Neurosci 30:99-122. CrossRef Medline

Norman KA, Schacter DL (1997) False recognition in younger and older adults: exploring the characteristics of illusory memories. Mem Cognit 25:838-848. CrossRef Medline

Oler JA, Markus EJ (1998) Age-related deficits on the radial maze and in fear conditioning: hippocampal processing and consolidation. Hippocampus 8:402-415. CrossRef Medline

O’Neill J, Senior T, Csicsvari J (2006) Place-selective firing of CA1 pyramidal cells during sharp wave/ripple network patterns in exploratory behavior. Neuron 49:143-155. CrossRef Medline

Paz R, Pelletier JG, Bauer EP, Paré D (2006) Emotional enhancement of memory via amygdala-driven facilitation of rhinal interactions. Nat Neurosci 9:1321-1329. CrossRef Medline

Paz R, Bauer EP, Paré D (2007) Learning-related facilitation of rhinal interactions by medial prefrontal inputs. J Neurosci 27:6542-6551. CrossRef Medline

Pelletier JG, Apergis J, Paré D (2004) Low-probability transmission of neo- cortical and entorhinal impulses through the perirhinal cortex. J Neurophysiol 91:2079-2089. CrossRef Medline

Prull MW, Dawes LL, Martin AM 3rd, Rosenberg HF, Light LL (2006) Recollection and familiarity in recognition memory: adult age differences and neuropsychological test correlates. Psychol Aging 21:107-118. CrossRef Medline

Rapp PR, Deroche PS, Mao Y, Burwell RD (2002) Neuron number in the parahippocampal region is preserved in aged rats with spatial learning deficits. Cereb Cortex 12:1171-1179. CrossRef Medline

Recce ML, O'Keefe J (1989) The tetrode: an improved technique for multiunit extracellular recording. Soc Neurosci Abstr 15:1250.

Robitsek RJ, Fortin NJ, Koh MT, Gallagher M, Eichenbaum H (2008) Cognitive aging: a common decline of episodic recollection and spatial memory in rats. J Neurosci 28:8945-8954. CrossRef Medline

Ryan L, Cardoza JA, Barense MD, Kawa KH, Wallentin-Flores J, Arnold WT, Alexander GE (2012) Age-related impairment in a complex object discrimination task that engages perirhinal cortex. Hippocampus 22:19781989. CrossRef Medline

Sargolini F, Fyhn M, Hafting T, McNaughton BL, Witter MP, Moser MB, Moser EI (2006) Conjunctive representation of position, direction, and velocity in entorhinal cortex. Science 312:758-762. CrossRef Medline

Schimanski LA, Lipa P, Barnes CA (2013) Tracking the course of hippocampal representations during learning: when is the map required? J Neurosci 33:3094-3106. CrossRef Medline

Schmitzer-Torbert N, Jackson J, Henze D, Harris K, Redish AD (2005) Quantitative measures of cluster quality for use in extracellular recordings. Neuroscience 131:1-11. CrossRef Medline

Shen J, Barnes CA, McNaughton BL, Skaggs WE, Weaver KL (1997) The effect of aging on experience-dependent plasticity of hippocampal place cells. J Neurosci 17:6769-6782. Medline

Skaggs WE, McNaughton BL, Gothard KM, Markus EJ (1993) An information-theoretic to deciphering the hippocampal code. In: Advances in neural information processing (Hanson SJ, Cowan JD, Giles CL, eds), pp 1030-1037. San Mateo, CA: Morgan Kaufmann.

Spatz C (2011) Basic statistics: tales of distributions, 10th edition. Belmont, CA: Wadsworth Cengage Learning.

Spencer WD, Raz N (1995) Differential effects of aging on memory for content and context: a meta-analysis. Psychol Aging 10:527-539. CrossRef Medline

Thome A, Erickson CA, Lipa P, Barnes CA (2012) Differential effects of experience on tuning properties of macaque MTL neurons in a passive viewing task. Hippocampus 22:2000-2011. CrossRef Medline

Toner CK, Pirogovsky E, Kirwan CB, Gilbert PE (2009) Visual object pattern separation deficits in nondemented older adults. Learn Mem 16: 338-342. CrossRef Medline

Toth JP, Parks CM (2006) Effects of age on estimated familiarity in the process dissociation procedure: the role of noncriterial recollection. Mem Cognit 34:527-537. CrossRef Medline

Tsao A, Moser MB, Moser EI (2013) Traces of experience in the lateral entorhinal cortex. Curr Biol 23:399-405. CrossRef Medline

Wan H, Aggleton JP, Brown MW (1999) Different contributions of the hippocampus and perirhinal cortex to recognition memory. J Neurosci 19: 1142-1148. Medline

Wang H, Xie X, Li X, Chen B, Zhou Y (2006) Functional degradation of visual cortical cells in aged rats. Brain Res 1122:93-98. CrossRef Medline

Winters BD, Bussey TJ (2005) Glutamate receptors in perirhinal cortex mediate encoding, retrieval, and consolidation of object recognition memory. J Neurosci 25:4243-4251. CrossRef Medline

Woloszyn L, Sheinberg DL (2012) Effects of long-term visual experience on responses of distinct classes of single units in inferior temporal cortex. Neuron 74:193-205. CrossRef Medline

Zhu XO, Brown MW (1995) Changes in neuronal activity related to the repetition and relative familiarity of visual stimuli in rhinal and adjacent cortex of the anaesthetised rat. Brain Res 689:101-110. CrossRef Medline

Zhu XO, Brown MW, Aggleton JP (1995) Neuronal signalling of information important to visual recognition memory in rat rhinal and neighbouring cortices. Eur J Neurosci 7:753-765. CrossRef Medline 